\title{
Weakening and Shifting of the Saharan Shallow Meridional Circulation during Wet Years of the West African Monsoon ${ }^{\mathfrak{O}}$
}

\author{
RAVI SHEKHAR AND WILLIAM R. BOOS
}

Yale University, New Haven, Connecticut

(Manuscript received 27 September 2016, in final form 5 June 2017)

\begin{abstract}
The correlation between increased Sahel rainfall and reduced Saharan surface pressure is well established in observations and global climate models and has been used to imply that increased Sahel rainfall is caused by a stronger shallow meridional circulation (SMC) over the Sahara. This study uses two atmospheric reanalyses to examine interannual variability of Sahel rainfall and the Saharan SMC, which consists of northward near-surface flow across the Sahel into the Sahara and southward flow near $700 \mathrm{hPa}$ out of the Sahara. During wet Sahel years, the Saharan SMC shifts poleward, producing a drop in low-level geopotential and surface pressure over the Sahara. Statistically removing the effect of the poleward shift from the low-level geopotential eliminates significant correlations between this geopotential and Sahel precipitation. As the Saharan SMC shifts poleward, its midtropospheric divergent outflow decreases, indicating a weakening of its overturning mass flux. The poleward shift and weakening of the Saharan SMC during wet Sahel years is reproduced in an idealized model of West Africa; a wide range of imposed sea surface temperature and land surface albedo perturbations in this model produce a much larger range of SMC variations that nevertheless have similar quantitative associations with Sahel rainfall, as in the reanalyses. These results disprove the idea that enhanced Sahel rainfall is caused by strengthening of the Saharan SMC. Instead, these results are consistent with the hypothesis that a stronger SMC inhibits Sahel rainfall, perhaps by advecting midtropospheric warm and dry air into the precipitation maximum.
\end{abstract}

\section{Introduction}

Over the twentieth century, large interannual and interdecadal variations in precipitation were observed in the African Sahel, producing occasional floods and sustained droughts. A variety of studies examined the cause of these variations (e.g., Charney et al. 1975; Folland et al. 1986; Eltahir and Gong 1996; Nicholson and Grist 2001), but a robust explanation was not established until Giannini et al. (2003) showed that much of the observed variability could be reproduced if observed global SSTs were used to drive a global climate model, implicating SST as the primary cause of historical Sahel precipitation changes.

While it is now generally agreed that SST drives interdecadal variations in Sahel precipitation (e.g.,

Supplemental information related to this paper is available at the Journals Online website: http://dx.doi.org/10.1175/ JCLI-D-16-0696.s1.

Corresponding author: Ravi Shekhar, ravi.shekhar@yale.edu
Nicholson 2013), the Sahara desert is also known to be associated with Sahel variability on a range of time scales. Haarsma et al. (2005) found a correlation on interannual time scales between increased Sahel rainfall and decreased mean sea level pressure over the Sahara. They argued that variations in the mean sea level pressure gradient between the Sahara and its surroundings cause variations in low-level convergence of mass and moisture, and thus in rainfall, over the Sahel. They furthermore argued that the mean sea level pressure gradient is set by the land-ocean temperature contrast, which can then be viewed as a fundamental driver of Sahel rainfall. In contrast, Biasutti et al. (2009) found that land-ocean temperature contrast is poorly correlated with Sahel precipitation at interannual time scales in models from phase 3 of the Coupled Model Intercomparison Project (CMIP3). They argued that variation in Sahel rainfall is caused by fluctuations in the Saharan low, an area of near-surface low pressure stretching across the Sahara desert. To quantify this, they calculated the index $\Delta Z 925$, defined as the difference in geopotential height at $925 \mathrm{hPa}$ between the 


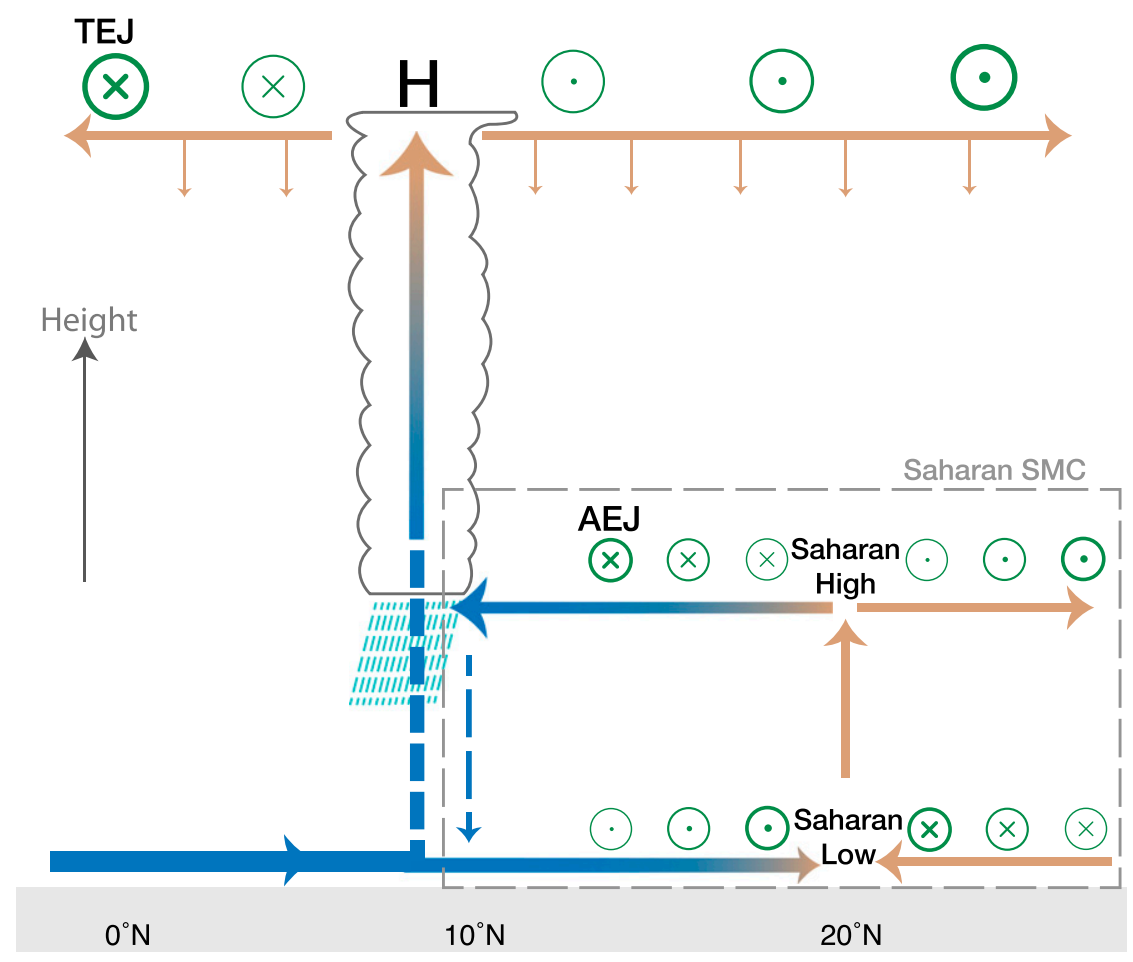

FIG. 1. The near-surface Saharan low is indicated at $20^{\circ} \mathrm{N}$, the midlevel Saharan high anticyclone is indicated at $20^{\circ} \mathrm{N}$, and the combination of these is collectively referred to as the Saharan SMC. The midlevel AEJ, upper-level tropical easterly jet (TEJ), and upper-level anticyclone in the ITCZ are also shown to help orient the reader.

Sahara desert and the global tropics. When this index was anomalously low, Sahel precipitation was high. Furthermore, a lead-lag correlation showed this $\Delta \mathrm{Z} 925$ index was maximally correlated with Sahel precipitation when the index led by one month, suggesting that Saharan low anomalies cause Sahel rainfall variability.

The studies just discussed treat the low-level circulation over the Sahara as an entity that can be described in terms of the distribution of mean sea level pressure or $925-\mathrm{hPa}$ geopotential height. However, this circulation consists of a geopotential height minimum at $925 \mathrm{hPa}$ over the Sahara and a geopotential height maximum in the lower midtroposphere (near $700 \mathrm{hPa}$ ) over the Sahara, with cyclonic and anticyclonic winds rotating around the nearsurface geopotential minimum and the $700-\mathrm{hPa}$ geopotential maximum, respectively. Figure 1 provides a schematic of this well-known structure of the Saharan circulation (e.g., Thorncroft et al. 2011). In addition to the balanced cyclonic and anticyclonic flow, mass converges into the near-surface low, ascends, and diverges out of the lower midtropospheric high in an ageostrophic overturning circulation. This shallow overturning, which we refer to as the Saharan shallow meridional circulation (SMC), extends across the entire Sahara desert: Fig. 2 clearly shows near-surface poleward flow across the Sahel extending from the west coast of Africa to the East African highlands at nearly $40^{\circ} \mathrm{E}$, with return flow at $700 \mathrm{hPa}$ extending over the same region (the data and methods used to create this figure are described in the next section). Shallow meridional circulations have been documented over Africa (Trenberth et al. 2000), in the eastern Pacific Ocean (e.g., Zhang et al. 2004; Nolan et al. 2007, 2010), and in the Australian monsoon (Nie et al. 2010). In continental monsoons such as those in Africa, the ascent branch of the SMC is located poleward of the ascent branch of the deep, precipitating intertropical convergence zone (ITCZ), whereas the ascent in the east Pacific SMC is spatially coincident with the ITCZ (Zhang et al. 2008).

The idea that a stronger Saharan SMC causes increased Sahel precipitation in the summer mean was stated explicitly by Martin and Thorncroft (2014), who examined differences in the West African monsoon between warm and cold phases of the Atlantic multidecadal oscillation (AMO). They found Sahel precipitation was enhanced during decades when the North Atlantic was warm, and they stated that the Saharan SMC was stronger during the spring (April-June) immediately preceding the summer rainy season (JulySeptember) of those decades. However, enhanced 

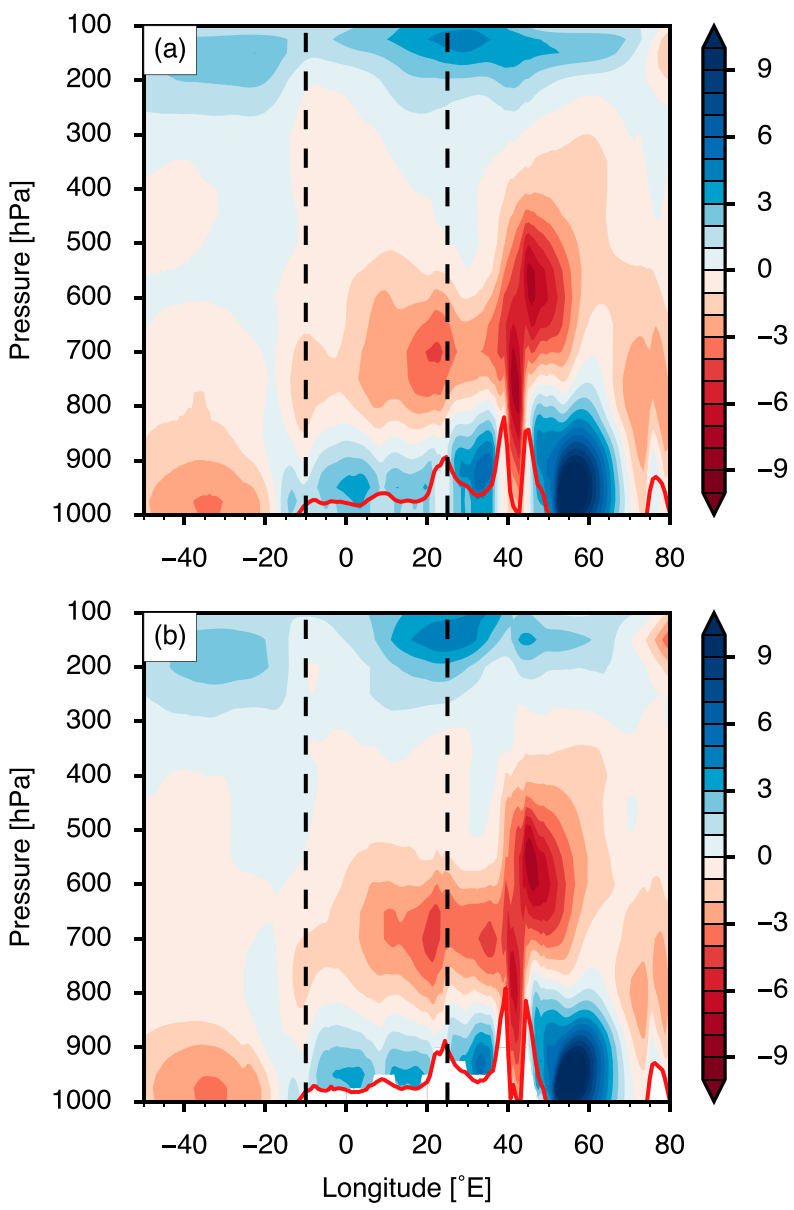

FIG. 2. JAS climatological meridional wind $v$ at $14^{\circ} \mathrm{N}$ for (a) ERA-Interim and (b) MERRA-2. The $10^{\circ} \mathrm{W}$ and $25^{\circ} \mathrm{E}$ boundaries indicated by black dashed lines. Surface pressure indicated by a bold red line.

springtime ascent in their analysis was centered over the Sahel and extended to the upper troposphere, with southward flow out of that ascending region located at $600 \mathrm{hPa}$ and higher altitudes; in contrast, ascent in the Saharan SMC is typically confined below $600 \mathrm{hPa}$, with the southward outflow centered at $700 \mathrm{hPa}$. Furthermore, Hurley and Boos (2013) found that 700-hPa equatorward outflow from continental SMCs weakened during anomalously rainy years of the West African, southern African, Australian, and South Asian monsoons. Thus, wet Sahel years seem to be characterized by something other than a simple intensification of the Saharan SMC. Interpretation of the structures seen in the analysis of Martin and Thorncroft (2014) are complicated by the coarse resolution of the NCEPNCAR reanalysis (Kalnay et al. 1996) that they employed, which has only three to four vertical levels that span the entire SMC overturning. One of our present goals is to use more recent atmospheric reanalyses to describe the detailed changes in structure and intensity of the Saharan SMC that accompany interannual changes in Sahel precipitation-interannual variability in the last 30 years is expected to be better constrained by observations than interdecadal variability over the last 100 years.

The Saharan SMC is related to the Saharan heat low, but the two terms describe distinct atmospheric structures. A heat low or thermal low is a warm region of the atmosphere that has large thickness by the hypsometric relation; these lows are typically confined below 600 or $700 \mathrm{hPa}$ and are sites of low surface pressure (e.g., Rácz and Smith 1999). They include the horizontal balanced flow and the ageostrophic overturning circulations illustrated in Fig. 1. Although the lower troposphere is hot and thus has large thickness across the entire Saharan desert, the term Saharan heat low (SHL) is now commonly used to describe the region of maximum low-level atmospheric thickness (LLAT) that exists over the western Sahara (e.g., Lavaysse et al. 2009) and is distinct from the Saharan low, which is the region of low surface pressure that extends across all of northern Africa (e.g., Biasutti et al. 2009). The 700-hPa anticyclone in the upper part of the SHL is highly asymmetric, with its southward-flowing eastern branch stretching across the entire eastern half of northern Africa during summer while northward flow in its western branch is weaker and confined to the northwest African coast (Thorncroft et al. 2011). The SMC that extends across northern Africa (e.g., Fig. 2) should thus not be thought to consist only of ageostrophic flow down the pressure gradient of the SHL but as a combination of ageostrophic and nondivergent, balanced winds that stretch across all of northern Africa.

In the western Sahara, links between the SHL and central Sahel rainfall have been studied on a range of time scales. Lavaysse et al. (2009) showed that the SHL exhibits a pronounced seasonal cycle and moves poleward to its boreal summer position around $20^{\circ}-30^{\circ} \mathrm{N}$, $7^{\circ} \mathrm{W}-5^{\circ} \mathrm{E}$ just before the onset of the West African monsoon, climatologically in late June. On intraseasonal and synoptic time scales, strong phases of the SHL are associated with increased moisture transport into the Sahel at low levels, accompanied by increased moisture convergence (e.g., Pu and Cook 2012) and precipitation over the central and eastern Sahel (Lavaysse et al. 2010a). Evan et al. (2015) examine the linear trend in the SHL between 1983 and 2009, showing a water vaporforced warming of the SHL, somewhat consistent with recent work showing amplified warming over the Sahara (Vizy and Cook 2017). Lavaysse et al. (2016) show that synoptic and intraseasonal variability of the SHL can influence the seasonal-mean Sahel precipitation, 
although the mechanisms by which these variations influence rainfall remain unclear.

Studies of the SHL in the western Sahara (e.g., Lavaysse et al. 2010a,b) and of the Saharan low that spans all of northern Africa (Haarsma et al. 2005; Biasutti et al. 2009) suggest that increased Sahel precipitation is caused by a decrease in Saharan surface pressure (or near-surface geopotential), which in turn drives an intensification of the mass flux in the Saharan SMC (Martin and Thorncroft 2014). However, some studies suggest that the sign of the association between Sahel rainfall and the Saharan SMC should be reversed, with a stronger SMC causing reduced rainfall. Peyrillé et al. (2007) and Peyrillé and Lafore (2007) used an idealized, zonally symmetric model of the West African monsoon to examine the influence on Sahel rainfall of the large-scale temperature and moisture advection produced by the Saharan SMC. They used an atmospheric reanalysis to show that the Saharan SMC produces near-surface cooling and moistening over the Sahel and Sahara and warming and drying in the lower midtroposphere (around $700 \mathrm{hPa}$ ). When they separately imposed these low- and midlevel advective tendencies in their idealized model, they found that the low-level cooling and moistening caused increased Sahel rainfall, while the midlevel warming and drying caused decreased Sahel rainfall. The effect of the midlevel warming and drying dominated so that temperature and moisture advection in the Saharan SMC has a net inhibitory effect on Sahel rainfall. Furthermore, Zhang et al. (2008) suggested that the transport of hot and dry midtropospheric air into the Sahel precipitation maximum by the Saharan SMC inhibits the northward seasonal migration of the precipitation maximum during early summer. Midtropospheric outflow of hot and dry air from deserts has also been argued to inhibit rainfall in the Indian (Parker et al. 2016) and Australian (Xie et al. 2010) monsoons. This is consistent with the demonstrated sensitivity of precipitating convection to drying of the free troposphere above the boundary layer (Derbyshire et al. 2004; Holloway and Neelin 2009; Sobel and Schneider 2009). In summary, there is evidence for a stronger Saharan SMC having both a positive and negative influence on Sahel rainfall.

To the best of our knowledge, the observed association of interannual variations in Sahel rainfall with the detailed structure of the Saharan SMC has not been examined. It might seem reasonable to assume that the overturning in the Saharan SMC would strengthen as the near-surface Saharan low strengthens, but given the dominant effect of the midlevel warming and drying on Sahel rainfall suggested by an idealized study (Peyrillé and Lafore 2007), this would be inconsistent with observations of a strengthening of the near-surface Saharan low during rainy Sahel years. Perhaps low-level cooling and moistening by the Saharan SMC has a larger influence on Sahel precipitation in the real world than in the idealized model of Peyrillé and Lafore (2007), similar to suggestions for the role of these low-level tendencies in the observed seasonal northward migration of West African rainfall (e.g., Hagos and Cook 2007; Thorncroft et al. 2011; Peyrillé et al. 2016). Or perhaps the Saharan SMC does not strengthen as the near-surface Saharan low strengthens. Here, we seek to resolve these questions by examining the association of Sahel rainfall with the Saharan SMC at interannual time scales in two atmospheric reanalyses and an idealized model.

The next section of this paper describes our data sources and analysis methods. Section 3 discusses the climatology and basic features of the West African monsoon and Saharan SMC. Section 4 examines how the horizontal structure of the near-surface Saharan low and the Saharan high covary with Sahel precipitation and is followed by a section detailing the vertical structure of the circulation changes, with emphasis on the divergent component of the flow. Section 7 compares all of these observationally based results with output from an idealized $\beta$-plane model. We close with a discussion of implications and caveats in section 8 .

\section{Methods}

We obtain winds, geopotential height, temperature, and humidity from the ERA-Interim (Dee et al. 2011), which is produced by the European Centre for MediumRange Weather Forecasts (ECMWF) and is used here for 1979-2015. ERA-Interim is a third-generation reanalysis with data assimilation based on 12-hourly four-dimensional variational data assimilation (4DVar). The dynamics are calculated on a spectral T255 (approximately $80 \mathrm{~km}$ ) global grid, with 60 vertical levels from the surface to $0.1 \mathrm{hPa}$. We also use NASA's Modern-Era Retrospective Analysis for Research and Applications, version 2 (MERRA-2; Gelaro et al. 2017), which is a third-generation reanalysis produced on a $0.5^{\circ} \times 0.625^{\circ}$ cubed-sphere grid with 72 vertical levels from the surface to $0.1 \mathrm{hPa}$. MERRA-2 is not available for 1979, so here, we use 1980-2015. All climatologies and regressions shown here use ERA-Interim data unless MERRA-2 is explicitly indicated. MERRA-2 versions of all applicable figures are provided in the online supplemental material.

The Global Precipitation Climatology Project (GPCP) dataset (Adler et al. 2003), which is a combination of land rain gauge and satellite-based precipitation measurements, is used as the primary precipitation dataset for this 

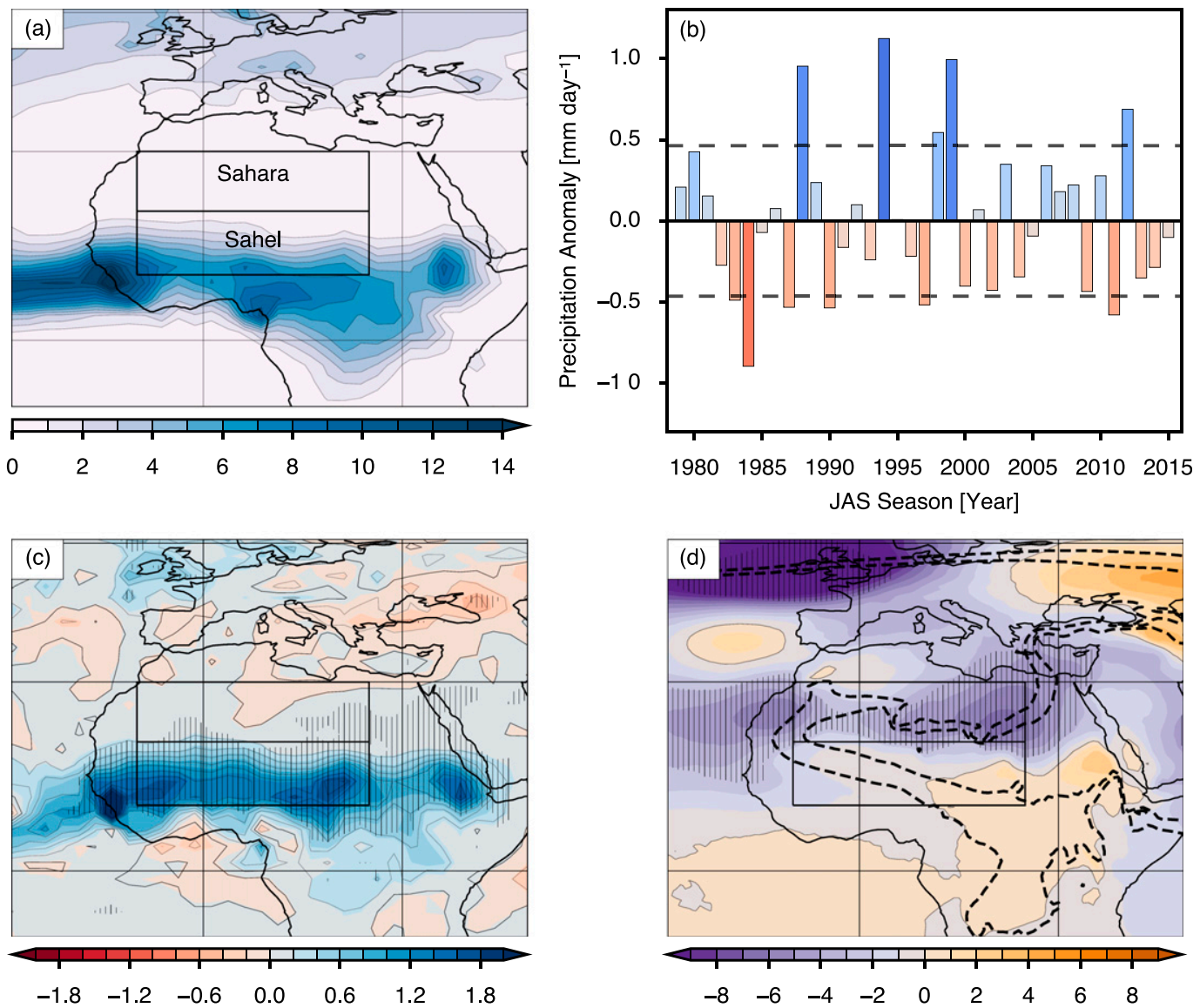

FIG. 3. (a) JJAS precipitation climatology $\left(\mathrm{mm} \mathrm{day}^{-1}\right)$ based on GPCP data, with Sahel and Sahara boxes indicated. (b) Detrended interannual time series of anomalous precipitation over the Sahel box derived from GPCP data, with plus or minus one standard deviation bounds indicated by dashed lines. (c) Regression slope of local detrended GPCP precipitation onto Sahel area-averaged precipitation $\left(\mathrm{mm}^{-1}\right.$ day). (d) ERA-Interim regression slope of detrended Z925 ( $\mathrm{m} \mathrm{mm}^{-1}$ day; colors) and climatological $\Delta$ Z925 (dashed contours mark -10 and $-20 \mathrm{~m}$ isolines). Statistically significant regression slopes $(p<0.05)$ are hatched.

study. The Global Precipitation Climatology Centre (GPCC; Schneider et al. 2014) dataset, based on corrected gridded rain gauge data, was also examined and found to produce no substantial changes in our conclusions. All data were obtained at monthly mean resolution.

We take seasonal averages over the July-September (JAS) season for all variables, as this is the peak of the Sahelian phase (e.g., Nicholson 2013) of the African monsoon. We conducted a sensitivity study to alternate choices of season, specifically June-September (JJAS) and July-August (JA), and found very few differences in our results. The average over all JAS periods in the reanalysis time period is referred to as the climatology. Figure 3a shows the GPCP JAS climatology of precipitation, with the Sahelian phase rainfall peak near $10^{\circ} \mathrm{N}$.

We are interested in the Saharan SMC (Fig. 2), so we choose $10^{\circ} \mathrm{W}-25^{\circ} \mathrm{E}$ as zonal bounds for our analyses. These zonal bounds encompass most of Northern
Hemisphere Africa but exclude coasts, the East African highlands, and the Arabian Desert. In the $10^{\circ} \mathrm{W}-25^{\circ} \mathrm{E}$ region, the latitudes from $10^{\circ}$ to $20^{\circ} \mathrm{N}$ are defined as the Sahel and from $20^{\circ}$ to $30^{\circ} \mathrm{N}$ as the Sahara, with both regions delineated with boxes in Fig. 3a. Anomalies of precipitation were calculated with respect to the JAS climatology, averaging over the Sahel box and subtracting the linear trend $\left(0.26 \pm 0.15 \mathrm{~mm} \mathrm{day}^{-1} \mathrm{decade}^{-1}\right)$ and the climatological mean $\left(3.31 \mathrm{~mm} \mathrm{day}^{-1}\right)$. The resulting time series is hereafter referred to as "Sahel precipitation" (Fig. 3b) and forms the basis of most regressions presented here. We also removed the linear trend from all other fields regressed against this Sahel precipitation time series. We detrend for two reasons: to highlight the interannual time scale for direct comparison with previous studies (e.g., Biasutti et al. 2009) and because analyzing trends in reanalyses can be problematic because of changes in the observational network 
over multiple decades. In particular, Vizy and Cook (2017) show that ERA-Interim features a drying trend over the Sahel that is inconsistent with observations. Our analysis supports this view (not shown), so we restrict ourselves to the interannual time scale. The trend removed accounts for approximately $27 \%$ of the total variance in summer-mean (JAS) Sahel precipitation.

Over the reanalysis period of 1979-2015, Sahel precipitation (as measured by GPCP) lacks statistically significant interannual autocorrelations (not shown), distinguishing variability in this more recent period from the persistent interdecadal droughts that characterized parts of the twentieth century and that were largely attributed to global variations in SST (Giannini et al. 2003). Losada et al. (2012) noted the nonstationarity of the relationship between Sahel precipitation and SST in the different ocean basins over the twentieth century and showed a marked transition in SST dependence in the 1970s, with a largely stationary regime of SST dependence since then. In our post-1970s period, precipitation variability at interannual time scales mostly exhibits a "monopole" spatial pattern (Fig. 3c), with single-signed precipitation anomalies extending from the Gulf of Guinea across the Sahel. This is in contrast to meridional "dipole" patterns of precipitation anomalies observed during the 1920s-70s [Fig. 14 of Nicholson (2013)]. These monopole and dipole patterns are specific to interannual time scales, and other patterns are observed at both shorter subseasonal and longer decadal time scales. This has implications for the generality of our results, which we discuss further in section 8 .

As many studies on the SHL focus on the $10^{\circ} \mathrm{W}-10^{\circ} \mathrm{E}$ region, we examined the sensitivity of our results to the zonal bounds, with precipitation time series created by averaging over the western portion $\left(10^{\circ} \mathrm{W}-10^{\circ} \mathrm{E}\right)$ and eastern parts $\left(10^{\circ}-25^{\circ} \mathrm{E}\right)$ of the Sahel. These two time series were highly correlated at interannual time scales, with a coefficient of determination of $R^{2}=0.72$. Furthermore, both eastern and western Sahel precipitation time series were individually very highly correlated $\left(R^{2}>0.9\right)$ with the precipitation time series presented in Fig. 3b. The entire analysis presented here was repeated for the eastern and western portions of the domain, with the appropriate eastern or western precipitation time series. The appendix explores some modest differences between these eastern and western subdomains, but our general conclusions also hold in these subdomains. This lack of sensitivity to the zonal bounds is consistent with the Saharan SMC (Fig. 2) and interannual variations in Sahel rainfall (Fig. 3c) being coherent across the entire zonal extent of Africa. Lavaysse et al. (2016) regress GPCP precipitation on a metric of SHL strength, in contrast to our method of regressing precipitation onto the area-averaged Sahel precipitation, and also obtain coherent rainfall anomalies across the entire Sahel $\left(10^{\circ}-\right.$ $20^{\circ} \mathrm{N}, 10^{\circ} \mathrm{W}-25^{\circ} \mathrm{E}$ ) at certain time scales (see their Fig. 11d). It is worth noting that Lavaysse et al. (2016) showed the positive or negative correlation between SHL strength and Sahel rainfall was time-scale dependent and zonally heterogeneous. The similarity we find between the eastern and western portions of the domain may thus not apply on time scales other than interannual.

For the idealized model portion of this study, we analyzed the same integrations presented in Shekhar and Boos (2016). These used the Weather Research and Forecasting (WRF) Model, version 3.3 (Skamarock et al. 2008), modified to run on an equatorial $\beta$ plane in a meridional channel at $15-\mathrm{km}$ resolution with 41 vertical levels. The domain was $20^{\circ} \times 140^{\circ}$ in the zonal and meridional directions, respectively, with periodic boundary conditions in the zonal direction and closed boundary conditions in the meridional direction. A continent was prescribed from $5^{\circ}$ to $32^{\circ} \mathrm{N}$, divided into a grassland from $5^{\circ}$ to $12^{\circ} \mathrm{N}$ and a desert from $12^{\circ}$ to $32^{\circ} \mathrm{N}$, with interactive surface temperature but prescribed soil moisture and other properties from the WRF land surface database. The remainder of the domain was ocean with a prescribed, idealized SST distribution representative of that observed during boreal summer near Africa. Perpetual 15 July insolation was imposed, with the diurnal cycle retained. As shown by Xie and Saiki (1999), fixed SST, prescribed soil moisture, and perpetual summer form a physically consistent set of simplifications, and allowing any one to be more realistic requires allowing all three to be more realistic to avoid unphysical variability, which would greatly increase computational requirements. A total of 13 model integrations were performed for one model year after a 3-month spinup, yielding the same amount of output for each integration as four 3-month summer seasons. One integration was chosen as the control, and others were forced by modifications of the specified desert surface albedo, the prescribed SST, or both. These form an ensemble of integrations in which the monsoon precipitation varies in response to the SST and surface albedo forcings. These integrations were documented more thoroughly in Shekhar and Boos (2016), where they were used to examine energy-based diagnostics of ITCZ location.

Statistical analyses were performed using Python programming language packages Iris (Met Office 2015), Seaborn (Waskom et al. 2016), and Statsmodels (Seabold and Perktold 2010). For linear regressions, we test for a nonzero slope using the two-sided Student's $t$ test at the $p<0.05$ level. For some linear regressions, we 
also obtain a $95 \%$ confidence interval for the slope using a bootstrapping technique on the joint probability distribution of slope and intercept, as given in the Seaborn package. We tested the sensitivity of linear regressions to outliers using the robust regression (e.g., Rousseeuw and Leroy 2005) feature of the Statsmodels package, and although certain confidence intervals narrow and shift slightly, no substantial qualitative differences were obtained. We also examined the possibility of using nonlinear (quadratic and cubic) models for regression and found a statistical preference for nonlinear models for less than $4 \%$ of grid points at the $95 \%$ confidence level, an amount attributable to chance.

\section{Basic features of the Saharan low and SMC}

We begin by examining the association of interannual variations in the Saharan low with those of Sahel rainfall, then detailing the climatological mean structure of the Saharan SMC. Although these analyses resemble those published previously (e.g., Biasutti et al. 2009; Thorncroft et al. 2011), the results confirm that the main features of interest are found in the ERA-Interim and MERRA-2 reanalyses and serve as a necessary reference for the rest of this paper.

Biasutti et al. (2009) obtained a correlation of high Sahel rainfall and negative anomalies of $925-\mathrm{hPa}$ geopotential height (Z925) over the Sahara desert. We reproduce this correlation in reanalyses (Fig. 3d). A regression of mean sea level pressure on Sahel rainfall (as in Haarsma et al. 2005) yields a similar pattern (not shown). These previous studies interpreted these patterns of Z925 and mean sea level pressure as indicative of a strengthening of the Saharan low. But the nearsurface Saharan low stretches zonally across northern Africa and is centered around $20^{\circ} \mathrm{N}$ while the decrease in Z925 is confined to the northern and western sides of that climatological trough. Since a strengthening of the Saharan low would consist of negative anomalies of Z925 centered over the climatological minimum Z925, the concentration of negative anomalies northward and westward of that climatological minimum indicates that the Saharan low is expanding northward and westward rather than simply strengthening. Much of the northward expansion occurs over northeastern Africa, consistent with the patterns in anomalous Z925 and mean sea level pressure seen in Biasutti et al. (2009) and Haarsma et al. (2005).

The near-surface Saharan low is part of the threedimensional Saharan SMC, as mentioned in the introduction. The ascending branch of the Saharan SMC is strongest at $20^{\circ} \mathrm{N}$ in the climatological and zonal mean (Figs. 4a,b). An examination of the zonal structure in the appendix shows the latitude of peak ascent moves equatorward as one moves east, from $23^{\circ} \mathrm{N}$ in the west to $19^{\circ} \mathrm{N}$ in the east. Low-level mass convergence occurs between the surface and $800 \mathrm{hPa}$, with peak convergence at $925 \mathrm{hPa}$ in the near-surface Saharan low. Divergence occurs in the $800-550-\mathrm{hPa}$ layer, with peak divergence at $700 \mathrm{hPa}$ associated with the Saharan high. The 925- and 700-hPa levels are taken as representative of the near-surface Saharan low and the Saharan high, respectively, in the next two sections. The maximum deep ascent in the ITCZ is located much farther south, around $8^{\circ} \mathrm{N}$ in ERA-Interim (Fig. 4a) and $6^{\circ} \mathrm{N}$ in MERRA-2 (Fig. 4b). Vertical structures of vertical velocity are somewhat different between the two reanalyses, perhaps because of differences in convective parameterizations. There is weak time-mean divergence and subsidence in the near-surface layer around $10^{\circ} \mathrm{N}$ in the precipitating region, a likely signal of strong time-mean subsidence and sporadic ascent due to precipitation.

The near-surface zonal and meridional winds change sign around $20^{\circ} \mathrm{N}$ in the climatological zonal mean (Figs. 4c,d). This change in sign, a feature sometimes described as the intertropical discontinuity (ITD), is not entirely zonally symmetric and shifts equatorward by a few degrees latitude as one moves eastward within our analysis domain (see section 4). Around $700 \mathrm{hPa}$, there is a peak in the equatorward flow as air travels in the timemean Saharan SMC toward the ITCZ. The African easterly jet (AEJ; e.g., Thorncroft and Blackburn 1999) exists in thermal wind balance around $600 \mathrm{hPa}$ and $14^{\circ} \mathrm{N}$. At upper levels, the tropical easterly jet, meridional flow in the upper branch of the Hadley circulation, and the midlatitude jet stream are also visible. In the next two sections, we examine how the strength and spatial structure of the Saharan SMC covary with Sahel precipitation.

\section{Horizontal structure of Saharan SMC changes}

Since the geopotential height and divergent wind together provide a nearly complete depiction of the horizontal circulation, we start by examining the horizontal structure of geopotential and divergent wind variations at 925 and $700 \mathrm{hPa}$. Figure 5a shows the $925-\mathrm{hPa}$ climatological trough extending across northern Africa during JAS around $20^{\circ} \mathrm{N}$. The previously discussed ITD exists at the center of this trough, which shifts slightly toward the equator in the eastern portion of the domain. Geostrophic flow moves cyclonically around the trough (not shown). The ageostrophic winds converge into the trough, and cross-equatorial southerly flow in the lowlevel branch of the Hadley cell is also visible over the Gulf of Guinea. When regressed on Sahel precipitation, we see a spatially heterogeneous but nearly single-signed 

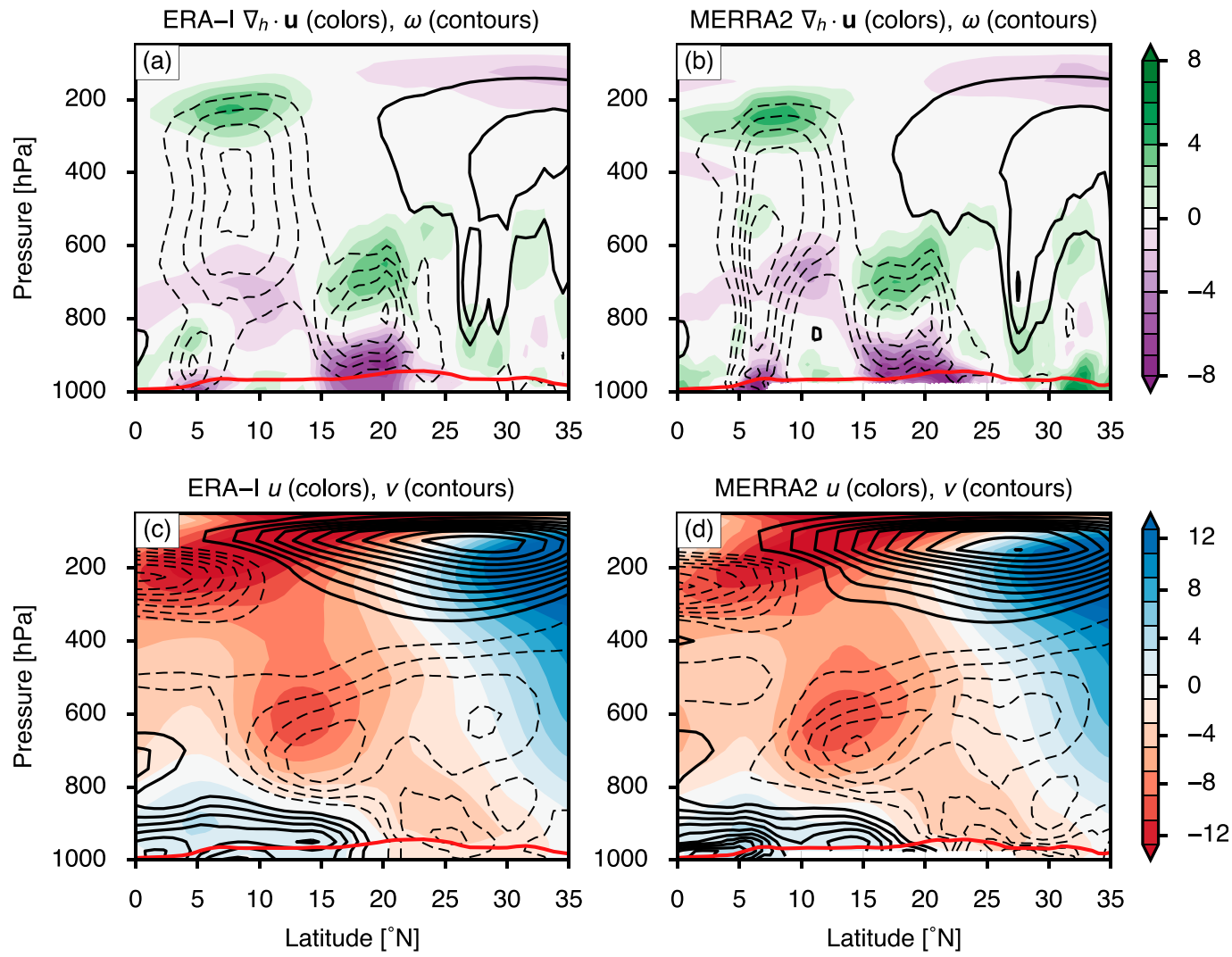

FIG. 4. (left) ERA-Interim and (right) MERRA-2 climatological JAS zonal mean (a) divergence (colors; $10^{-6} \mathrm{~s}^{-1}$ ) and (b) pressure velocity $\omega$ (contours every $0.5 \mathrm{hPa} \mathrm{h}^{-1}$ ). (c),(d) Zonal wind $u$ (colors) and meridional wind $v$ (contours every $\mathrm{m} \mathrm{s}^{-1}$ ). All panels have zero contours omitted, and negative contours are dashed.

decrease in Z925 (Fig. 5b) north of $20^{\circ} \mathrm{N}$ over northern Africa and portions of the Atlantic (the dynamical implications of this decrease are discussed in the next two sections). Although changes in Z925 are not statistically significant over the Sahel, there are weak anomalies of northerly divergent flow in the southern Sahel during wet years that indicate a weakening of the ageostrophic northward monsoon flow at $925 \mathrm{hPa}$. At the northern boundary of the Sahel, anomalous southerly wind flows across the climatological ITD into the region of anomalously low Z925. Effectively, this moves the ITD and minimum of the Saharan low poleward during wet years (a quantitative measure of the meridional shift in the Saharan low is provided in the next section).

Figure $5 \mathrm{c}$ shows the horizontal structure of the climatological mean Saharan high, with gradients in Z700 in geostrophic balance with an anticyclone over most of the Saharan region. There is a substantial zonal gradient in Z700 over the central and eastern Sahara and a sharp meridional gradient over the Sahel in balance with the AEJ. The peak in climatological Z700 lies poleward and westward of the trough in climatological Z925.
Downgradient divergent flow occurs south and northwest of the $700-\mathrm{hPa}$ high, constituting the divergent northerly outflow in the upper branch of the Saharan SMC. The regression of Z700 onto Sahel precipitation (Fig. 5d) shows a statistically significant decrease centered in the Sahel, implying a strong anomalous cyclonic circulation during wet years. This midlevel anomalous cyclone is also visible at $600 \mathrm{hPa}$ (not shown) and is well supported by observational evidence of a northward shift and weakening in the AEJ during wet Sahel years (e.g., Nicholson 2013). At $700 \mathrm{hPa}$, the anomalous divergent wind converges into the center of the anomalous low, around $15^{\circ} \mathrm{N}$ in the eastern Sahel.

We expect the 925- and 700-hPa surfaces to be affected differently by a strengthening of the shallow SMC compared to a strengthening of the deep, precipitating monsoon circulation. A stronger shallow SMC is expected to be accompanied by a reduction in Z925 in the Saharan low, an increase in Z700 in the Saharan high, and an intensification of the divergent, overturning circulation that flows down the geopotential gradients at these two levels. In contrast, enhanced precipitation is expected to be accompanied by enhanced ascent in a 

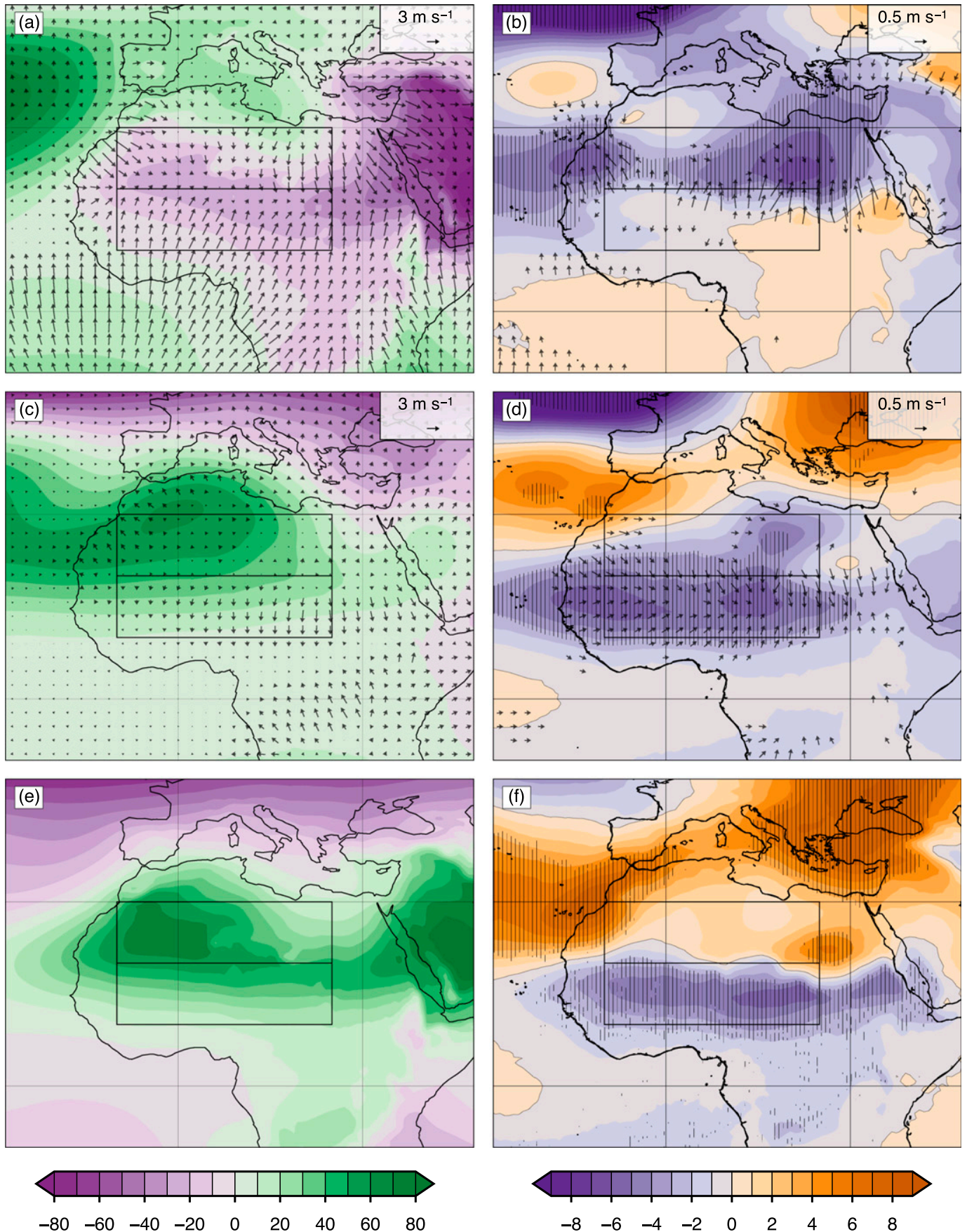

FIG. 5. All panels use ERA-Interim data. Colors show climatological JAS (a) Z925, (c) Z700, and (e) LLAT (all units in meters). Constant values of 790,3150, and $2260 \mathrm{~m}$, respectively, were subtracted to reduce them to the same color scale. Arrows show the divergent component of the wind $\mathbf{u}_{\chi}$ for the same 925-and 700-hPa levels, respectively. Colors show the regression slope of detrended (b) Z925, (d) Z700, and (f) LLAT onto GPCP Sahel precipitation respectively $\left(\mathrm{m} \mathrm{mm}^{-1}\right.$ day), with hatched regions indicating statistical significance. Divergent wind regression slope for same 925- and 700-hPa levels, respectively, shown in arrows, with only regions where $u_{\chi}$ or $v_{\chi}$ is statistically significant and $\left|\mathbf{u}_{\chi}\right|>0.1 \mathrm{~m} \mathrm{~s}^{-1} \mathrm{~mm}^{-1}$ day are drawn. 


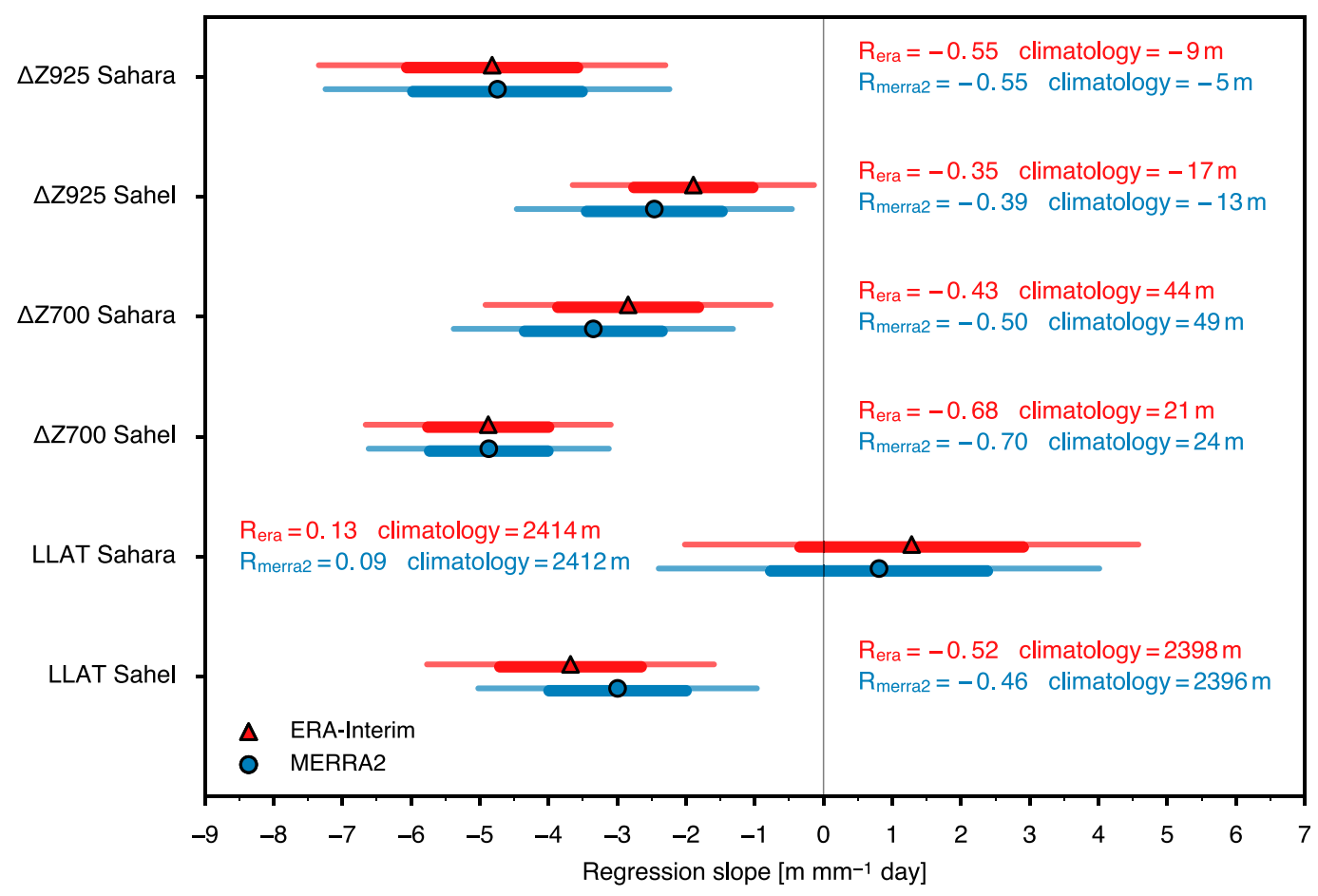

FIG. 6. The $\Delta \mathrm{Z} 925, \Delta \mathrm{Z700}$, and LLAT were averaged over the Sahara and Sahel in both ERA-Interim and MERRA-2, detrended, and regressed against Sahel precipitation; 68\% (thick) and 95\% (thin) confidence intervals of the regression slope are shown. Climatological values of each quantity and the Pearson $R$ coefficient of the regression are indicated on the figure. Critical $R$ values with $n-2=34$ degrees of freedom are $0.329,0.423$, and 0.525 at the $0.05,0.01$, and 0.001 levels.

deep circulation that can be approximated by a firstbaroclinic mode; strengthening of such a first-baroclinic mode will include decreases in geopotential height in the entire lower and middle troposphere and increases in geopotential in the upper troposphere [see Neelin and Zeng (2000) for a derivation of the structure of a typical tropical first-baroclinic mode and Zhang et al. (2008) or Nie et al. (2010) for illustration of how the shallow Saharan SMC coexists with a precipitating first-baroclinic mode structure over West Africa]. The 925- and 700-hPa surfaces are thus expected to have opposite vertical displacements as the Saharan SMC intensifies, simply because the Saharan LLAT would need to increase to maintain a stronger ageostrophic overturning, absent any large changes in drag. In contrast, those two surfaces are both expected to move downward as the deep, precipitating circulation strengthens. Figures $5 \mathrm{~b}$ and $5 \mathrm{~d}$ show that the 700- and 925-hPa surfaces both move downward during wet Sahel years, providing no evidence for a strengthening of the shallow SMC. Furthermore, when geopotential heights are averaged over our Sahel and Sahara boxes, statistically significant negative anomalies in Z925 and Z700 are found during wet years in both regions (Fig. 6). Thus, geopotential variations at 925 and $700 \mathrm{hPa}$ are inconsistent with the hypothesis that the Saharan SMC strengthens during wet Sahel years.

These changes in structure can also be viewed in terms of the thickness of the lower troposphere, but one must remember that LLAT will increase during a strengthening of the shallow heat low circulation and during a strengthening of the deep precipitating circulation. Shifts in the midlatitude barotropic flow (e.g., the jet stream) can also project on LLAT. The LLAT climatology (Fig. 5e) shows a maximum over the western Sahara, with relatively high LLAT extending east along the $20^{\circ} \mathrm{N}$ parallel, approximately following the ITD. Thus, although the Saharan heat low is commonly thought of as being confined to the western Sahara (e.g., Lavaysse et al. 2009), a band of high LLAT extends eastward across the entire Sahara into the Arabian desert heat low.

The regression of LLAT onto Sahel precipitation (Fig. 5f) shows increases in LLAT centered to the northeast and northwest of our Saharan box, but the regression slope is not statistically distinct from zero over most of the Sahara. Over nearly all of the Sahel, a statistically significant decrease in the LLAT is apparent. The weak zonal variation in the anomalies shown in the right column of Fig. 5 is important: there is no 
thickening of the lower troposphere in the western Sahara, where the LLAT is climatologically highest. If the Saharan heat low or the Saharan SMC were strengthening, we would see increased LLAT at the climatological maximum LLAT. The substantial increases in LLAT over eastern Europe, the Mediterranean, and the Atlantic might indicate interactions with the midlatitudes, perhaps through mechanisms proposed by Vizy and Cook (2009) and Lavaysse et al. (2010b). In summary, there is a decrease in LLAT on the equatorward side of the maximum LLAT, and the strong increases in LLAT are centered off the coasts of Africa, poleward of the LLAT maximum. The changes in LLAT thus seem more consistent with a poleward shift, rather than a strengthening, of the thermal low and the Saharan SMC during wet years. These results do not change appreciably if an alternate upper bound (e.g., 600 or $500 \mathrm{hPa}$ ) is used to define the LLAT, which would allow us to capture a deepening of the heat low (e.g., Evan et al. 2015).

We have thus far examined variations in geopotential height, but it is horizontal gradients in geopotential that are dynamically relevant. Changes in these gradients can be assessed by eye in maps of the horizontal distribution of geopotential, but we now wish to horizontally average the changes in geopotential over our analysis regions. So for every JAS season, we subtract the tropicalmean $\left(23^{\circ} \mathrm{S}-23^{\circ} \mathrm{N}\right.$, indicated with square brackets) geopotential height from the actual height at each pressure level: $\Delta Z=Z-[Z]_{\text {global_tropics }}$. This methodology, which was also performed by Biasutti et al. (2009), eliminates dynamically inconsequential changes in geopotential associated with tropical-mean warming or cooling due to, for example, ENSO.

Regressions of detrended $\Delta Z$ on Sahel precipitation quantitatively reproduce the result, shown by Biasutti et al. (2009), of decreased Saharan $\Delta$ Z925 during wet Sahel years (Fig. 6). The ERA-Interim results are quantitatively indistinguishable from the MERRA-2 results. We also see decreased $\Delta$ Z925 over the Sahel, and an inspection of the climatological values (text insets in Fig. 6) indicates that the meridional gradient of $\Delta$ Z925 between the Sahara and Sahel flattens during wet years. The Sahel LLAT decreases as a consequence of $\Delta Z 925$ decreasing less than $\Delta Z 700$ during wet years (in this case, removal of the tropical mean has nearly zero effect, with variations in $\Delta Z 700-\Delta Z 925$ being nearly equal to variations in Z700 - Z925). This is inconsistent with the idea that a classic first-baroclinic mode structure intensifies over the Sahel, and we will show in the next section that the vertical profile of the anomalous convergence during wet years also differs from that of a classic first-baroclinic mode but still provides no evidence for a strengthening of the Saharan low during wet years. Changes in Saharan LLAT are not statistically distinguishable from zero. This analysis confirms that, even when data are horizontally averaged, no strengthening of the Saharan SMC can be detected in the LLAT.

Since we found some evidence of a northward expansion of the Z925 trough into the Sahara during wet Sahel years (Fig. 5b), we ask how much of the change geopotential can be attributed to a simple meridional shift of the trough. We define the "trough latitude" by taking a $10^{\circ} \mathrm{W}-25^{\circ} \mathrm{E}$ zonal average of $\Delta \mathrm{Z} 925$ then finding the latitude of the minimum, using cubic splines to interpolate between reanalysis grid points. The trough latitude exhibits a modest positive correlation with Sahel rainfall (Fig. 7a), with a slope of $0.50^{\circ} \pm 0.22^{\circ} \mathrm{mm}^{-1}$ day in ERA-Interim. Both reanalyses contain an influential data point in 1984, the driest year in the reanalysis period, with the trough latitude about $1^{\circ}$ farther equatorward in that year than in all other years. Removing this extreme data point or using robust linear regression decreases slopes to approximately $0.45^{\circ} \mathrm{mm}^{-1}$ day but does not qualitatively change the relationship between the trough latitude and Sahel precipitation. The MERRA-2 data exhibit a somewhat bimodal distribution in trough latitude for which we do not have an explanation.

The trough latitude might be influenced by changes in both the thermal low and the deep, precipitating circulation, so we also examine the latitude of the maximum zonally averaged LLAT as a more direct measure of the position of the thermal low (Fig. 7b). The latitude of maximum LLAT typically lies a few degrees poleward of the trough latitude and also has higher interannual variability. Nevertheless, it shows a northward shift of the zonally averaged thermal low during wet Sahel years. The regression slopes for the 925-hPa trough latitude and the latitude of maximum LLAT are statistically indistinguishable (i.e., their confidence intervals overlap).

We now return to the question of how much of the drop in Saharan $\Delta Z 925$ can be attributed to a poleward shift of the trough into the Sahara and answer this question by statistically removing the effect of this shift from the Saharan $\Delta Z 925$. The regression of Saharan $\Delta Z 925$ on trough latitude produces a slope of $-4.8 \pm 2.5 \mathrm{~m}$ ( $^{\circ}$ latitude $)^{-1}$ (Fig. $7 \mathrm{c}$ ). When this dependence is subtracted from the Saharan-averaged $\Delta$ Z925 to create a "latitude-detrended $\Delta$ Z925," the resulting quantity has no statistically significant relationship with Sahel precipitation (Fig. 7d). This suggests that previous findings of changes in the Saharan low during wet Sahel years (e.g., Haarsma et al. 2005; Biasutti et al. 2009) should be interpreted as a shift of 

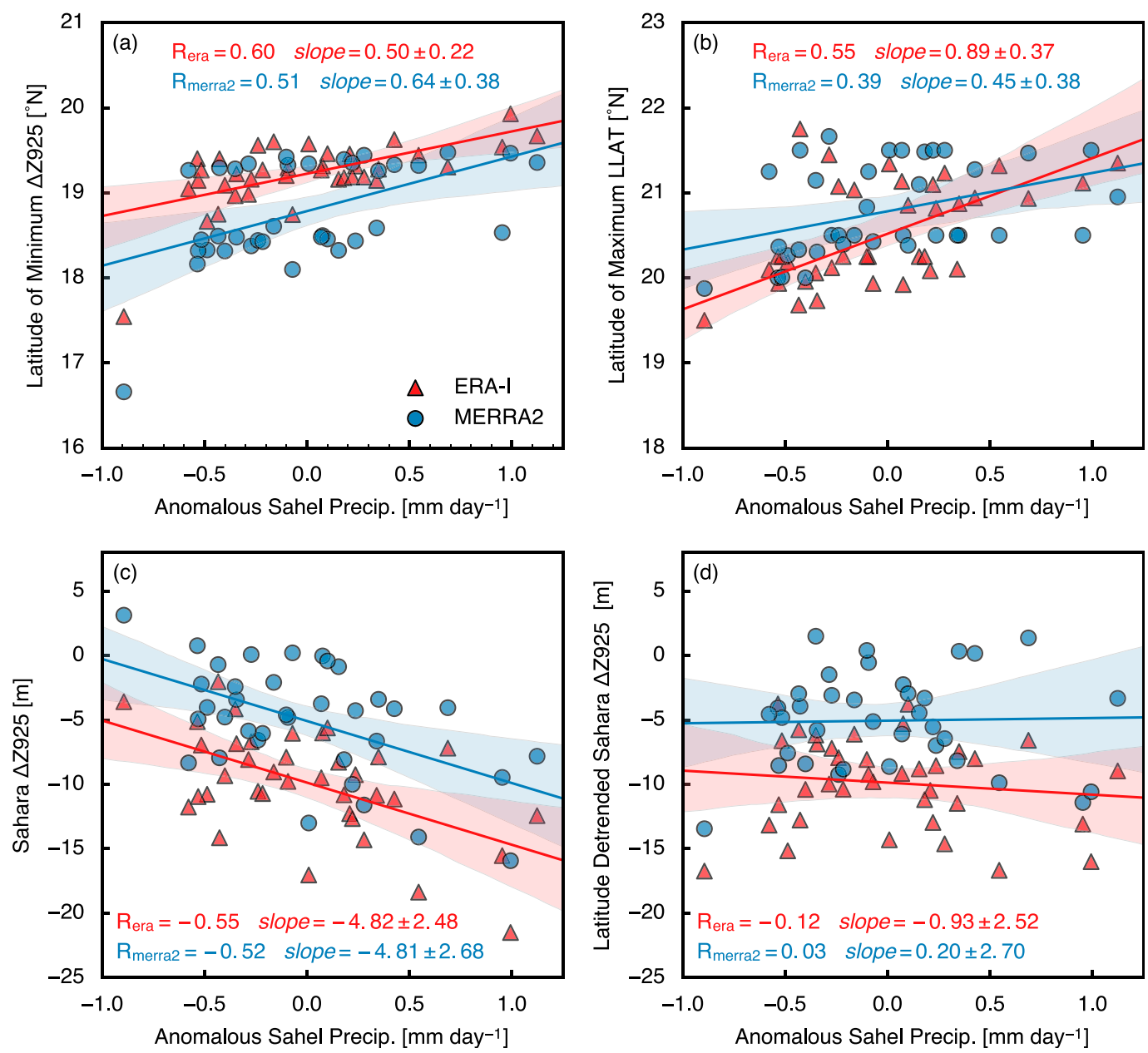

FIG. 7. Regressions against Sahel precipitation of (a) $925-\mathrm{hPa}$ trough location (latitude of minimum 925-hPa $\Delta$ Z925), (b) latitude of maximum LLAT, (c) Sahara $\Delta$ Z925, and (d) Sahara $\Delta Z 925$ with linear dependence on heat low trough location removed. All quantities had the long-term time trend removed after area averaging.

the low-level trough into the Sahara. As the next section will show, many dynamic and thermodynamic quantities also show a poleward shift.

\section{Vertical structure of changes in the Saharan SMC}

We now examine the vertical structure of interannual variations in the West African monsoon circulation, with focus on the Saharan SMC. We first briefly examine the poleward shift of the SMC during wet monsoon years then discuss variations in the strength of the divergent component of the circulation. While a few of the vertical structures shown here were presented in previous work (e.g., Nicholson and Grist 2001; Nie et al. 2010; Lavaysse et al. 2010a), they are included to provide a complete picture of the dynamical changes that constitute a weakening and poleward shift of the Saharan SMC.
The climatological low-level potential temperature is maximum around $22^{\circ} \mathrm{N}$ (Fig. 8a), poleward of the ITD. As Sahel precipitation increases, there is substantial cooling over the Sahel below $700 \mathrm{hPa}$, likely due to evaporative cooling of the land surface and reduced surface sensible heat fluxes into the boundary layer, though enhanced meridional advection of cool air into the region may also play a role poleward of $15^{\circ} \mathrm{N}$ where the meridional wind anomaly is positive (Fig. 8g). Above $700 \mathrm{hPa}$, warming occurs poleward of $10^{\circ} \mathrm{N}$ into the midlatitudes. By the hypsometric relation, this has a direct impact on the $\Delta Z$ climatology (Fig. 8b), which shows the near-surface Saharan low centered around $18^{\circ} \mathrm{N}$ in the climatology and the midtropospheric Saharan high centered around $25^{\circ} \mathrm{N}$. The regression of $\Delta Z$ onto Sahel precipitation (Fig. 8 b) shows that these structures expand northward or shift northward at every level. The cooling of the Sahel during wet years (Fig. 8a) 

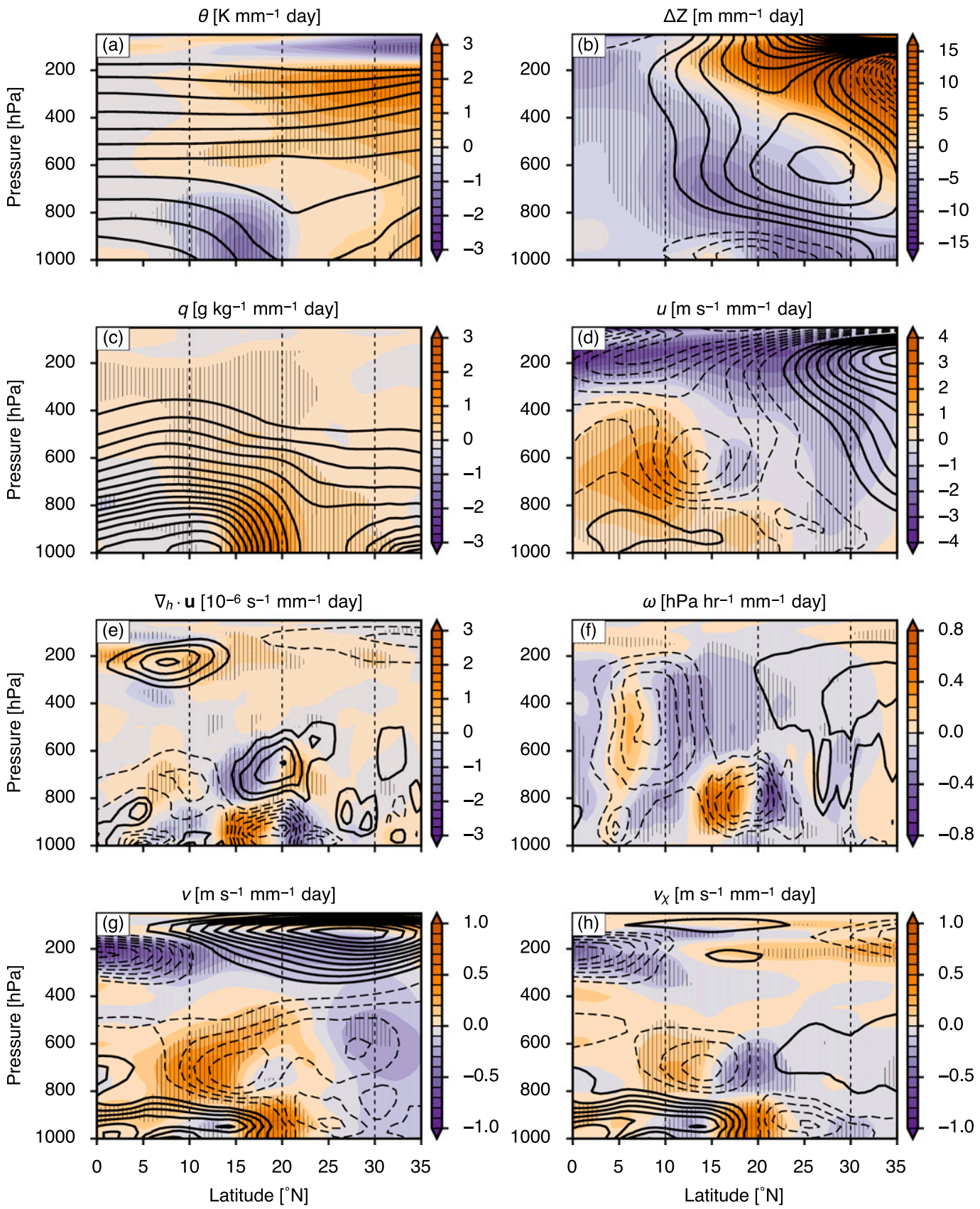

FIG. 8. All panels show ERA-Interim zonal averages over $10^{\circ} \mathrm{W}-25^{\circ} \mathrm{E}$. Colors indicate regression slope of the detrended quantity onto Sahel precipitation, hatching indicates statistical significance, and black contours indicate climatology (negative dashed, zero omitted). Units on regression slope imply $\mathrm{mm}^{-1}$ day. (a) $\theta$ (K; contours every $5 \mathrm{~K})$; (b) $\Delta Z$ (m; contours every $10 \mathrm{~m})$; (c) specific humidity $\left(\mathrm{g} \mathrm{kg}^{-1}\right.$; contours every $\left.1 \mathrm{~g} \mathrm{~kg}^{-1}\right)$; (d) $u\left(\mathrm{~m} \mathrm{~s}^{-1}\right.$; contours every $\left.2 \mathrm{~m} \mathrm{~s}^{-1}\right)$; (e) horizontal divergence $\left(10^{-6} \mathrm{~s}^{-1}\right.$; contours every 1$)$; (f) $\omega\left(\mathrm{hPa} \mathrm{h}^{-1}\right.$; contours every $\left.0.5 \mathrm{hPa} \mathrm{h}^{-1}\right)$; (g) $v\left(\mathrm{~m} \mathrm{~s}^{-1}\right.$; contours every $\left.0.5 \mathrm{~m} \mathrm{~s}^{-1}\right)$; and $(\mathrm{h}) v_{\chi}\left(\mathrm{m} \mathrm{s}^{-1}\right.$; contours every $\left.0.5 \mathrm{~m} \mathrm{~s}^{-1}\right)$.

is, by hydrostatic balance, accompanied by a thinning of the layer below $700 \mathrm{hPa}$ and an anomalous low in the midtroposphere (Fig. 8b). The cooling of the southern part of the Saharan low is accompanied by an increase in specific humidity (Fig. 8c) that is larger, in energy units, than the decrease in temperature, so that the low-level equivalent potential temperature $\theta_{e}$ is higher over the Sahel during wet years (Hurley and Boos 2013). The zonal wind (Fig. 8d) has been previously reviewed in Nicholson (2013), and here, we simply make the point 
that the northward shift and weakening in the AEJ during wet years is consistent with the midlevel anomalous cyclonic circulation over the Sahel shown in Figs. $5 \mathrm{~d}$ and $8 \mathrm{~d}$.

The poleward shift in the Saharan SMC can be seen as an anomalous, meridionally asymmetric quadrupole pattern in the anomalous divergence below $550 \mathrm{hPa}$ (Fig. 8e; note the vertical dipole in the climatological mean fields centered at $20^{\circ} \mathrm{N}$ ). There is also a meridional expansion of the upper-tropospheric divergence associated with the monsoonal ITCZ. This upper-tropospheric feature is also visible in the vertical velocity (Fig. 8f), with more deep ascent over the Sahel during wet years accompanying the anomalous dipole in low-level ascent that indicates a poleward shift in the Saharan SMC. Consistent with the regression of horizontal divergence, this dipole in shallow ascent is also not meridionally symmetric, with more anomalous subsidence than ascent during wet years. There are also zonal asymmetries in the anomalies of shallow ascent, with the anomalous subsidence near $17^{\circ} \mathrm{N}$ more pronounced in the western part of our domain and the anomalous ascent near $22^{\circ} \mathrm{N}$ more pronounced in the eastern part (see appendix).

The meridional wind regression (Fig. 8g) shows an asymmetric quadrupole as well, with the southerly lobes of the quadrupole being spatially larger and of greater amplitude than the northerly lobes. However, this asymmetry in the anomalous meridional wind should not be interpreted as a weakening of the divergent circulation because we are considering a limited zonal mean, in which the nondivergent component of meridional flow does not have to equal zero. When only the divergent component of the meridional wind is considered (Fig. 8h), the meridional asymmetry in this quadrupole is substantially reduced. But to the degree that the Saharan SMC consists of both divergent and rotational components, its equatorward outflow at $700 \mathrm{hPa}$ is clearly reduced during wet Sahel years (Fig. 8g).

In the next section, we better quantify interannual variations in the divergent part of the circulation. This allows us to understand how the increased mass divergence in the upper troposphere that accompanies enhanced Sahel precipitation (Fig. 8e) is compensated by increased convergence at lower levels. It also allows us to assess whether asymmetries in the meridional dipoles of shallow ascent and divergence are statistically significant and thus indicate a weakening of the Saharan SMC.

\section{Changes in layer-integrated divergence}

The vertical section of divergence (Fig. 8e) allows identification of three layers that largely capture the changes in the divergent circulation: the lower troposphere $(1000-800 \mathrm{hPa})$, the middle troposphere $(800$ $550 \mathrm{hPa})$, and the upper troposphere $(350-100 \mathrm{hPa})$. Taking a mass-weighted vertical integral of divergence over each layer (and over the remaining 550-350-hPa layer in which little divergence occurs), we see the climatological signatures of the divergent Hadley circulation and the Saharan SMC (Figs. 9a,c). In the lower layer, the largest convergence is due to the shallow circulation; this peaks near $20^{\circ} \mathrm{N}$ and is stronger in ERAInterim than in MERRA-2. There is also relatively weak convergence in the ITCZ near $8^{\circ} \mathrm{N}$. The middle troposphere exhibits large divergence at $20^{\circ} \mathrm{N}$ and substantial convergence at $10^{\circ} \mathrm{N}$. Upper-level divergence peaks around $8^{\circ} \mathrm{N}$, the latitude of maximum precipitation and deep ascent; the roughly equal magnitude and opposite signs of upper-tropospheric divergence and midtropospheric convergence at that latitude indicate that timemean inflow to the deep, continental convergence zone occurs not near the surface but in the lower midtroposphere. There is upper-level convergence poleward of about $15^{\circ} \mathrm{N}$, consistent with the northern Sahel and Sahara being regions of time-mean subsidence. Divergence in the $550-350-\mathrm{hPa}$ layer is comparatively small, and divergence above $100 \mathrm{hPa}$ is smaller still (not shown).

Regressing layer-integrated divergence onto Sahel precipitation (Figs. 9b,d) shows the now-familiar meridional dipole indicating a poleward shift of the climatological mean divergence field in the lower and midlayers, as well as a single-signed increase in uppertropospheric divergence over the Sahel region. The increase in upper-tropospheric divergence indicates increased deep ascent over the Sahel, consistent with precipitating convection. Near the climatological ITCZ, around $8^{\circ} \mathrm{N}$, upper-level divergence increases little, suggesting the ITCZ is expanding northward more than shifting northward. Farther north, in the shallow circulation around $20^{\circ} \mathrm{N}$, the asymmetry in the meridional shift is more clearly evident than in our previous depiction, with stronger changes on the equatorward lobe of the dipoles, implying that the Saharan SMC weakens as it shifts poleward. There are some differences between ERA-Interim and MERRA-2, with the negative anomaly of midlevel divergence being more intense in MERRA-2. Nevertheless, both reanalyses have asymmetric meridional dipoles in the anomalous lower- and midlevel divergence.

We wish to quantify any net change in strength of the Saharan SMC and determine if that change is statistically significant after removing the effect of the northward shift. To do this, we horizontally average the anomalous midlevel divergence over a domain large 

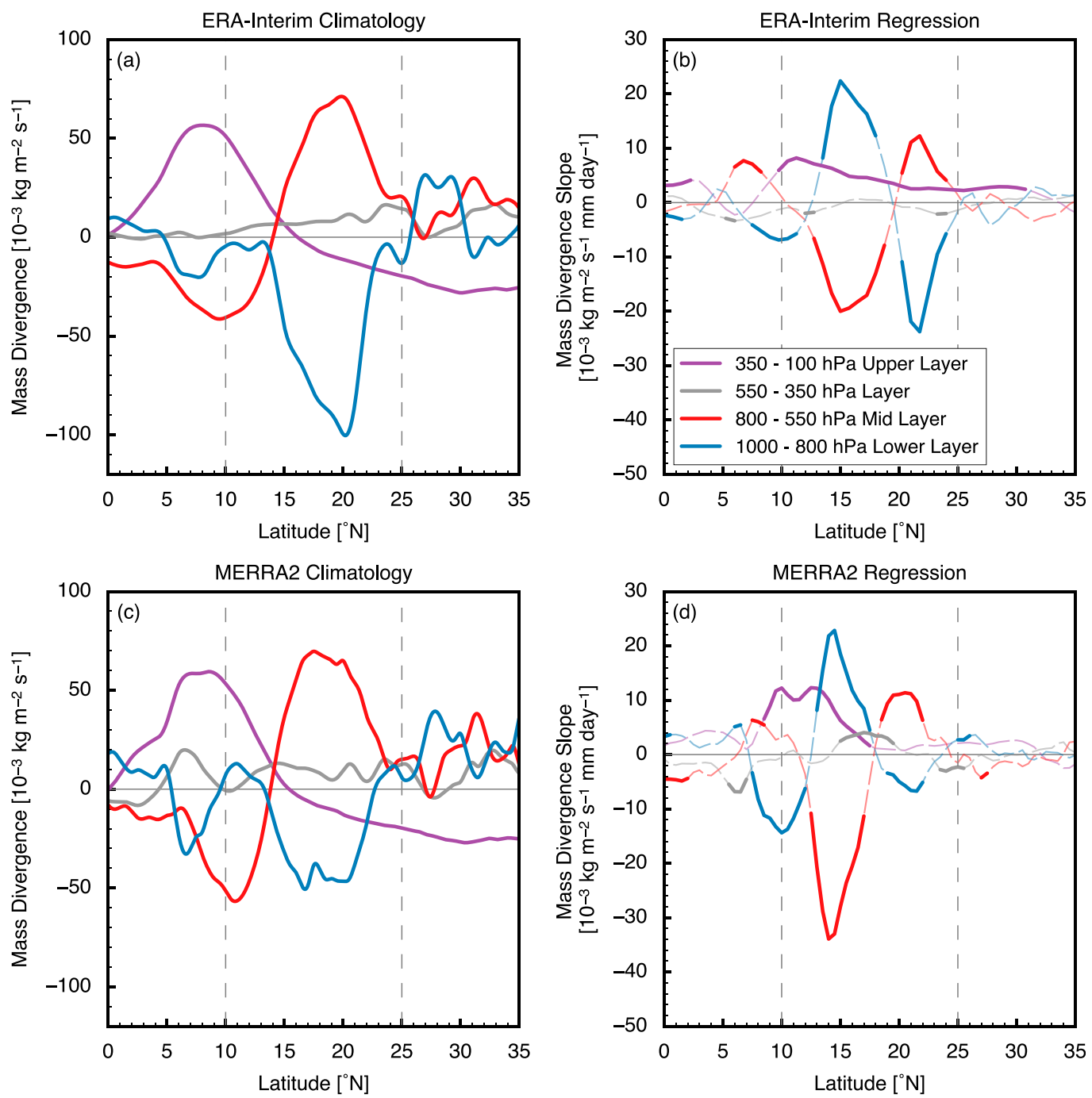

FIG. 9. (a) ERA-Interim climatological vertical integrals of zonally averaged divergence over the specified layers $\left(10^{-3} \mathrm{~kg} \mathrm{~m}^{-2} \mathrm{~s}^{-1}\right)$. (b) ERA-Interim regression slope of zonal and vertical integrals of anomalous divergence over the specified layers $\left(10^{-3} \mathrm{~kg} \mathrm{~m}^{-2} \mathrm{~s}^{-1} \mathrm{~mm}^{-1}\right.$ day). Statistically significant slopes are shown in dark, solid colors. (c),(d) As in (a) and (b), but for MERRA-2.

enough to encompass the meridional dipoles in that field. The changes in low- and midlevel divergence associated with the Saharan SMC are confined to the region between $10^{\circ}$ and $25^{\circ} \mathrm{N}$ (Figs. $8 \mathrm{e}$ and $9 \mathrm{~b}, \mathrm{~d}$ ). So we horizontally average the layer-integrated divergence anomalies over $10^{\circ}-25^{\circ} \mathrm{N}, 10^{\circ} \mathrm{W}-25^{\circ} \mathrm{E}$, thereby removing the antisymmetric component of the dipole and leaving a residual that corresponds to a net strengthening or weakening of divergence in each layer over the combined Sahel-Sahara region. The $10^{\circ} \mathrm{N}$ bound may be located slightly too far south and thus include divergence changes associated with shifts of the ITCZ, but those changes are expected to reduce the magnitude of any signal indicative of a weakening SMC (e.g., see the low- and midlevel anomalies in Fig. 8e). Indeed, averaging over the even larger region of $5^{\circ}-25^{\circ} \mathrm{N}$ decreases the magnitude of the net divergence variations (which are presented below) but does not qualitatively change the result.

The result of this area averaging of the layer-integrated divergence shows that during wet Sahel years, upperlevel divergence increases, midlevel divergence decreases, and any changes in low-level divergence are not statistically distinct from zero (Fig. 10a). Layer-averaged humidity also increases (this will be further discussed in the next section). A strengthening of the Saharan SMC would consist of a decrease in low-level divergence (enhanced convergence) and an increase in midlevel 

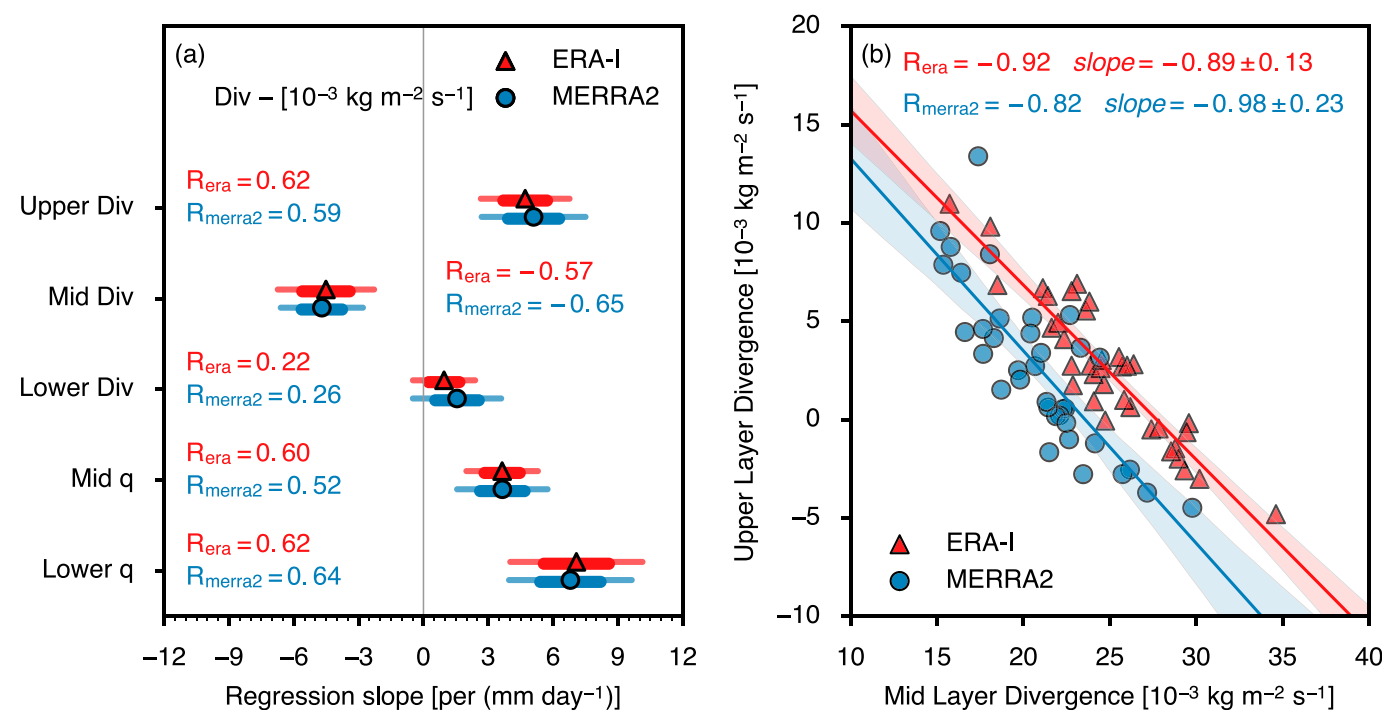

FIG. 10. (a) Vertically integrated divergence $\left(10^{-3} \mathrm{~kg} \mathrm{~m}^{-2} \mathrm{~s}^{-1}\right)$ or layer-averaged specific humidity $\left(10^{-1} \mathrm{~g} \mathrm{~kg}^{-1}\right)$ detrended and regressed against GPCP Sahel precipitation. The $68 \%$ (thick) and $95 \%$ (thin) confidence intervals are shown for the slope of the regression along with the Pearson $R$. (b) Regression of detrended upper-tropospheric divergence onto detrended midtropospheric divergence. All quantities are horizontal averages over $10^{\circ}-25^{\circ} \mathrm{N}$, $10^{\circ} \mathrm{W}-25^{\circ} \mathrm{E}$.

divergence; our area-averaged results have the opposite sign at midlevels. Furthermore, Fig. 10b shows midlevel divergence is strongly anticorrelated with upper-level divergence, indicating that the enhanced uppertropospheric divergence during wet monsoon years is balanced, in the summer-mean column mass budget, by decreased midtropospheric divergence. This balance is quantitatively confirmed by the fact that the regression coefficient relating upper- and midlevel layer-integrated convergence is approximately -1 . Interannual variations in the deep, precipitating monsoon circulation thus cannot be captured by a classic first-baroclinic mode that has maximum convergence near the surface and divergence at upper levels. Thorncroft et al. (2011) showed that the climatological mean moisture flux convergence in the Sahel has a complicated vertical structure with a weak maximum in our midtropospheric layer associated with flow in the Saharan SMC, so it is perhaps not surprising that variations in the flow also do not have a simple classical structure. This issue is discussed further in the next section in the context of our idealized simulations.

\section{Model of a weakening and shifting Saharan SMC}

Our idealized WRF Model integrations, performed at $15-\mathrm{km}$ horizontal resolution on a zonally periodic $\beta$ plane, are detailed in section 2 and in Shekhar and Boos (2016). A variety of surface albedo and SST forcings were applied individually about a control state to form an ensemble of model integrations. Instead of examining interannual variability within individual integrations, we look at the intraensemble variability of the long-term time-mean state and compare it to interannual variability within the reanalyses. Because of the zonally symmetric boundary conditions of the idealized model, the time-mean zonal wind is nondivergent, and there are no large-scale dynamical forcings such as those associated with ENSO or the South Asian monsoon, which could produce differences between observed interannual variability and the model intraensemble variability. Nevertheless, we find quantitative similarities in the statistical association between simulated monsoon precipitation and multiple dynamical variables.

The ensemble members are strongly forced (e.g., Saharan albedo changes of 0.1-0.2) so represent a wider range of ITCZ and SMC locations than is observed in the modern historical record. After a spinup period, each ensemble member produces a different climatological state (averaged over four 3-month summer seasons) in response to the applied perturbations. Figure 11 shows how the time-mean mass streamfunction [obtained using the method of Döös and Nilsson (2011)] changes between integrations having the driest Sahel and those with the wettest Sahel (the model Sahel is also defined as the region $10^{\circ}-20^{\circ} \mathrm{N}$ ). In the ensemble member with the lowest precipitation, deep ascent peaks at $8^{\circ} \mathrm{N}$ and ascent in the SMC is well separated with a peak at $17^{\circ} \mathrm{N}$. In this state, the summer Hadley cell is strong, the cross-equatorial winter Hadley cell is relatively 


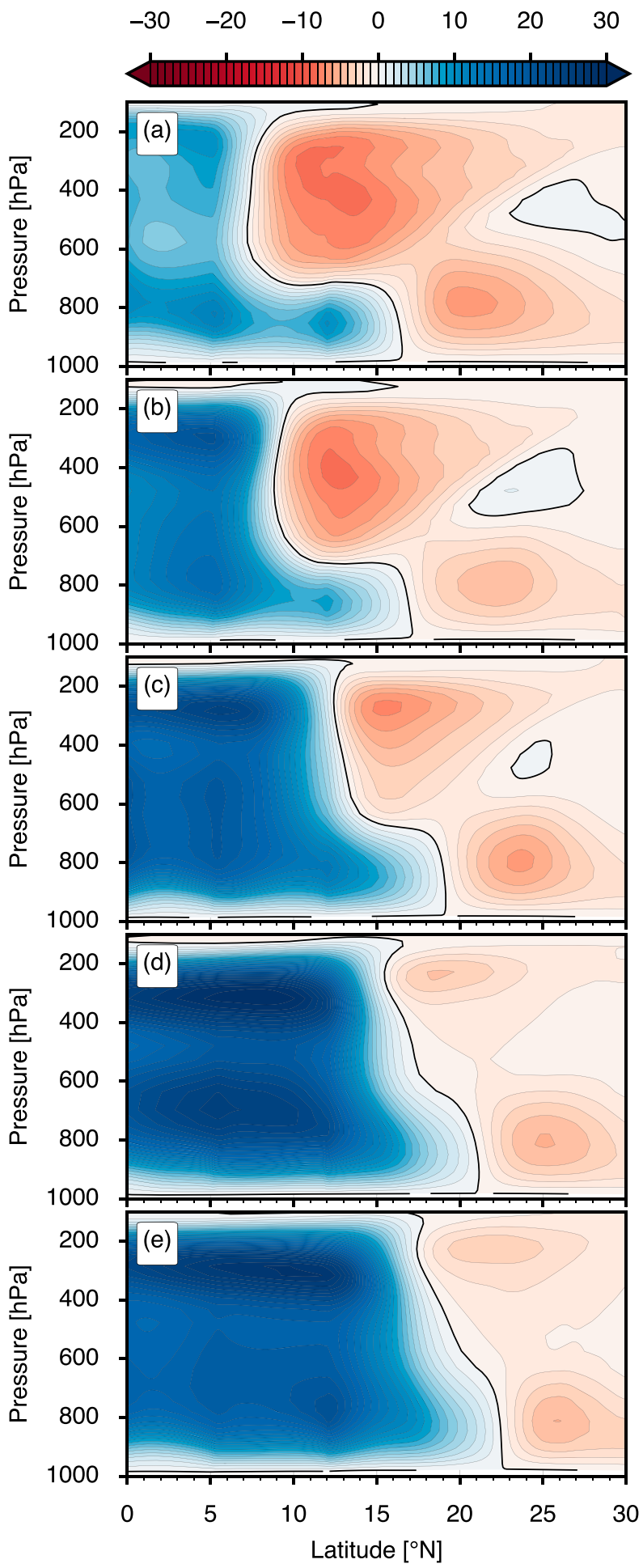

FIG. 11. Mass streamfunctions $\left(10^{9} \mathrm{~kg} \mathrm{~s}^{-1}\right)$ ordered by increasing precipitation in the $10^{\circ}-20^{\circ} \mathrm{N}$ box. (a) The $+2 \mathrm{~K} \mathrm{SST}$ forcing south of Africa. (b) Albedo increase of 0.10 over $12^{\circ}-32^{\circ} \mathrm{N}$. (c) Control experiment. (d) The $-2 \mathrm{~K}$ SST equatorial cold tongue, as in (a). (e) Albedo decrease of 0.10 over $12^{\circ}-32^{\circ} \mathrm{N}$. weak, and the SMC is relatively strong. As precipitation increases over the Sahel box (e.g., Fig. 11c), the ITCZ moves poleward into the continent, the winter Hadley cell strengthens, the summer Hadley cell weakens, and the separation between the SMC ascent and the ITCZ decreases. As Sahel precipitation increases further (e.g., Fig. 11e), the winter Hadley cell continues to strengthen, the summer Hadley cell continues to weaken, and the shallow SMC ascent begins to merge with the ITCZ.

Quantitatively comparing our idealized model with observations is complicated by the task of choosing an appropriate region over which to average precipitation and divergence. In the reanalyses, the Sahel $\left(10^{\circ}-20^{\circ} \mathrm{N}\right)$ always lies on the poleward edge of the ITCZ, and the ascending branch of the Saharan SMC is centered in the region over which we averaged divergence $\left(10^{\circ}-25^{\circ} \mathrm{N}\right)$. In the idealized model, the ITCZ and SMC move over a much wider latitude band, with the ITCZ centered south of the averaging region in some integrations and squarely within it in others (Fig. 11). Nevertheless, ascent in the model SMC always lies between $10^{\circ}$ and $25^{\circ} \mathrm{N}$, so variations in the strength of midtropospheric divergence produced by the Saharan SMC should be well captured by averages of the layer-integrated divergence between those latitude bounds. For this reason, we average precipitation and layer-integrated divergence over the same regions chosen for the reanalyses.

As expected, the observed interannual variability of both Sahel precipitation and SMC latitude is much smaller than variability in the model ensemble (Fig. 12a). There is quantitative agreement between the regression coefficients based on observed and simulated variables: the $95 \%$ confidence interval for the slope of model Sahel precipitation regressed on model SMC latitude overlaps with that of both ERAInterim and MERRA-2. The idealized model also exhibits associations between Sahel precipitation and upper-level divergence, midlevel convergence, and area-averaged, layer-integrated humidity that are quantitatively similar to those seen in observed interannual variability (Fig. 12b). This agreement is remarkable given that the model was not tuned to observed interannual variability: these simulations were performed for a different study (Shekhar and Boos 2016) that was completed before this analysis was undertaken. However, the idealized model disagrees with observations in that it simulates enhanced low-level convergence when there is enhanced Sahel precipitation (recall that the reanalyses indicate a weak reduction of low-level convergence during anomalously rainy years). Enhanced precipitating ascent in the idealized model thus seems to be better 

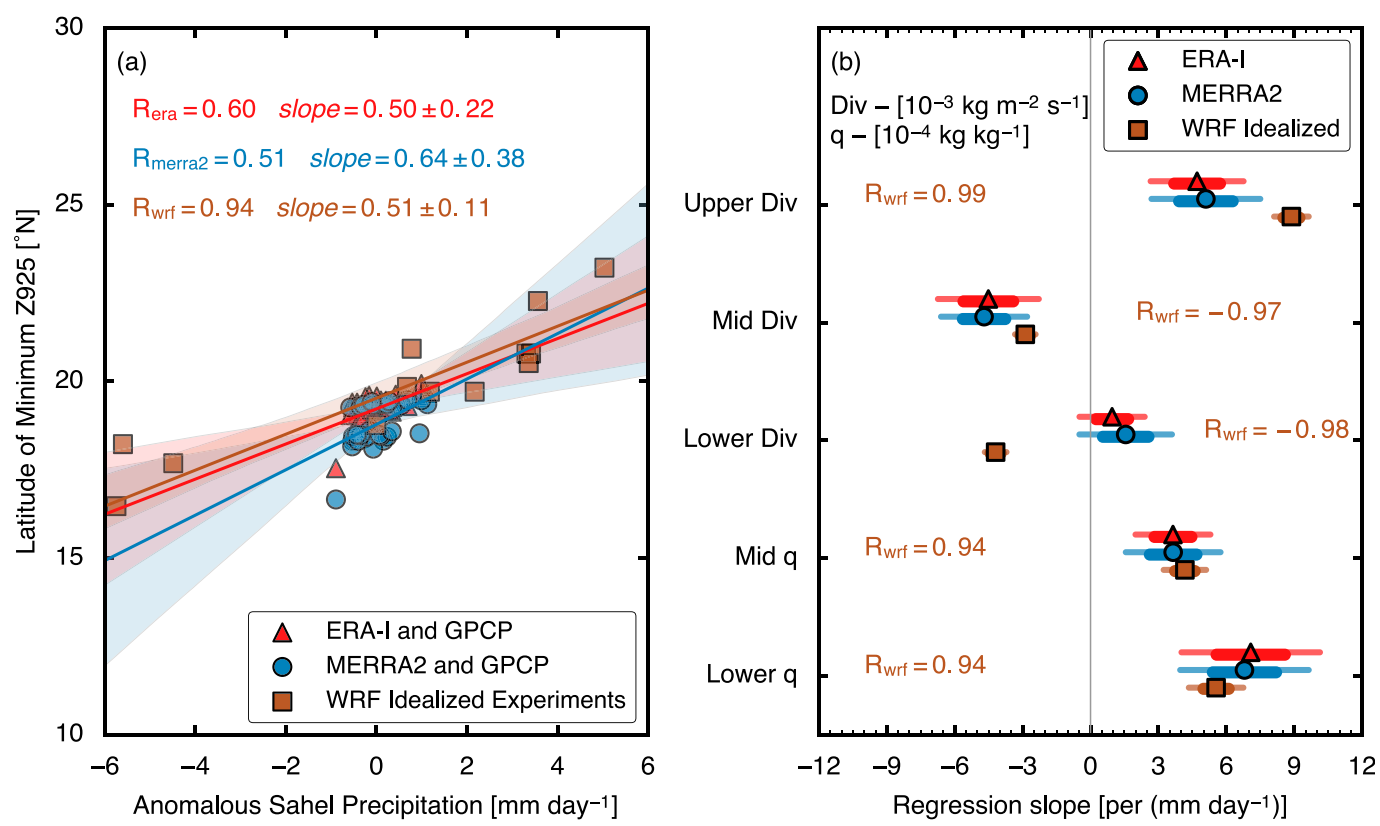

FIG. 12. (a) The trough location, the latitude of minimum $\Delta$ Z925, was calculated and regressed against precipitation. For reanalysis data, it was regressed against detrended GPCP Sahel precipitation, and for WRF idealized simulations, it was regressed against model precipitation. (b) The layer-integrated divergence $\left(10^{-3} \mathrm{~kg} \mathrm{~m}^{-2} \mathrm{~s}^{-1}\right)$ and specific humidity $\left(10^{-1} \mathrm{~g} \mathrm{~kg}^{-1}\right)$ were calculated, detrended in reanalyses and regressed against GPCP, or regressed against model Sahel precipitation. The $68 \%$ (thick) and $95 \%$ (thin) confidence intervals are shown for the regression slope. For the WRF confidence intervals, Pearson $R$ is shown, and because of a different number of degrees of freedom (11), critical $R$ values are $0.552,0.683$, and 0.800 at the $0.05,0.01$, and 0.001 significance levels.

described by a classic first-baroclinic mode vertical structure than in reanalyses. Whether this means that the model is unsuitable for representing interactions between the monsoonal ITCZ and the Saharan SMC is unclear, in large part because there has been little study of the implications of deviations from a firstbaroclinic mode structure for variability in monsoons.

Despite some bias in its simulation of the vertical structure of the ITCZ, this idealized model clearly simulates a weakening and poleward shift of the Saharan SMC circulation in states with enhanced Sahel precipitation. Furthermore, the model results suggest that the circulation over West Africa exists on a continuum. At one end of the continuum, dry states have a coastal ITCZ close to the equator, large separation between the ITCZ and ascent in the SMC, and a strong Saharan SMC circulation with abundant midtropospheric divergence. At the other end of the continuum, the ITCZ is positioned much farther poleward in a continental location, the winter Hadley cell is stronger while the summer Hadley cell is weaker, and the overturning mass flux and midtropospheric divergence in the Saharan SMC are weaker. In that state, which is an idealized analog of observed wet Sahel years, the ascending branches of the SMC and ITCZ have begun to merge to produce a vertical structure closer to that of first-baroclinic mode ascent common in deep convective regions.

\section{Discussion}

Previous work found intriguing associations between Sahel precipitation and the strength of both the Saharan low that stretches across Africa and the SHL in the western Sahara. At interannual and longer times scales, an enhancement of either the Saharan low or the SHL is associated with increased rainfall over the Sahel (e.g., Haarsma et al. 2005; Biasutti et al. 2009; Lavaysse et al. 2016, section 4). However, previous studies did not examine the detailed changes in the three-dimensional lower-tropospheric circulation that stretches across northern Africa-the Saharan SMC. Martin and Thorncroft (2014) argued that a strong springtime shallow meridional circulation across West Africa accompanied enhanced summer rainfall over the Sahel during decades when the North Atlantic was anomalously warm. Martin and Thorncroft (2014, p. 31) claimed that "the intensified shallow meridional overturning circulation increases moisture flux into the Sahel from the south during spring," describing a mechanism in which an intensified mass flux in an SMC causes enhanced Sahel rainfall. 
Here, we find the changes in lower-tropospheric winds and geopotential during wet Sahel years are best described as a poleward shift and weakening of the Saharan SMC. At low levels, the decrease in geopotential was located north of the climatological mean geopotential minimum, suggesting a northward expansion or shift, rather than an intensification, of the lowlevel trough during wet monsoon years. When the linear relationship between the $925-\mathrm{hPa}$ trough latitude and Sahel precipitation was statistically removed, effectively subtracting the poleward shift of the Saharan low from the geopotential field, no statistically significant relationship remained between Sahel precipitation and Saharan 925-hPa geopotential.

Our analyses of ascent and horizontal divergence showed that the divergent component of the Saharan SMC weakened and shifted poleward during wet Sahel years. Upper-tropospheric divergence over the Sahel increased during wet years, as expected for a deep, precipitating monsoon circulation. Shallow ascent in the Saharan SMC shifted poleward and weakened during wet years, as evidenced by the meridionally asymmetric dipole of anomalous vertical velocity in the lower troposphere over the Sahara (Fig. 8f). Asymmetric meridional dipoles were also seen in the divergence integrated over the lower and middle troposphere, confirming this weakening and poleward shifting of the shallow circulation. The increased upper-level divergence during wet years is balanced, in the column integrated mass budget, by decreased divergence in the lower midtroposphere, indicating some departure from classic first-baroclinic mode structures that have maximum convergence near the surface. Nevertheless, these results suggest a tradeoff between the shallow and deep modes of vertical ascent, where unusually wet years exhibit a stronger deep circulation and weaker Saharan SMC.

An idealized model of the West African monsoon was used to produce an ensemble of integrations forced by applied SST and land surface albedo anomalies. This ensemble explores a variety of climatic states with a much greater range than that of interannual variations in reanalyses. Nevertheless, without any tuning, the intraensemble variability of the idealized model climatological means exhibits a similar relationship between the Saharan SMC and Sahel precipitation seen in observed interannual variability. Increases in deep, precipitating ascent in the model were better described by a classic first-baroclinic mode than they were in reanalyses, but both the model and the reanalyses clearly showed a weakening of midtropospheric divergence in the Saharan SMC as monsoon precipitation increased.

All of this supports the hypothesis that the Saharan SMC inhibits, rather than strengthens, Sahel precipitation.
This is consistent with the results of Peyrillé and Lafore (2007), who showed that dry and warm outflow from the Saharan high weakened Sahel precipitation in another idealized model and that this weakening was stronger than any strengthening produced by an enhanced poleward moisture flux at low levels in the SMC. As mentioned in the introduction, Zhang et al. (2008) also suggested that midlevel warming and drying by SMC outflow inhibits the northward progression of Sahel rainfall during early summer. Studies of other monsoon regions have also provided evidence that a stronger SMC causes weaker monsoon rainfall: Xie et al. (2010) established a relationship between midlevel advective drying and reduced rainfall on intraseasonal time scales in the Australian monsoon, while Parker et al. (2016) showed that the summer onset of monsoon rains is accompanied by the weakening of midlevel advective drying. Although our observational results do not establish causation in the association between Sahel rainfall and the strength and location of the Saharan SMC, they do disprove the hypothesis that increased Sahel precipitation is caused by a strengthening of the SMC. In our idealized model, the ultimate cause of changes in precipitation was anomalies in SST and land surface albedo, but variations in the Saharan SMC could be part of the mechanism by which those forcings influence Sahel precipitation.

A few major caveats are worth noting. First, we focus on interannual variations of Sahel precipitation with the linear trend removed. As Lavaysse et al. (2016) show, at subseasonal and decadal time scales, the relationship between Sahel precipitation and the near-surface Saharan low is zonally heterogeneous, whereas we take largely a zonal mean approach to analyze the Saharan SMC. Second, we remove the long-term trends primarily for reasons of data quality, and there may be interesting trends in the SMC that we cannot detect. Third, Fig. 3c showed that variations in GPCP precipitation exhibit a "monopole" pattern over West Africa since 1979 on interannual time scales. The reanalysis precipitation fields in ERA-Interim and MERRA-2 show more of a dipole pattern of interannual variability over this period, with a statistically significant decrease in precipitation over the Gulf of Guinea $\left(5^{\circ}-10^{\circ} \mathrm{N}\right)$ during wet Sahel years (not shown). This dipole pattern of precipitation anomalies, which is consistent with a meridional shift of the ITCZ and which characterized rainfall variations earlier in the twentieth century (Losada et al. 2012), has not been seen in precipitation measurements after the 1970s. So it seems possible that the reanalyses are representing a biased spatial pattern of precipitation variability during the past few decades, assuming the precipitation observations are not themselves in error. This uncertainty in precipitation over the coastal Gulf of 
ERA-Interim JAS Climatology
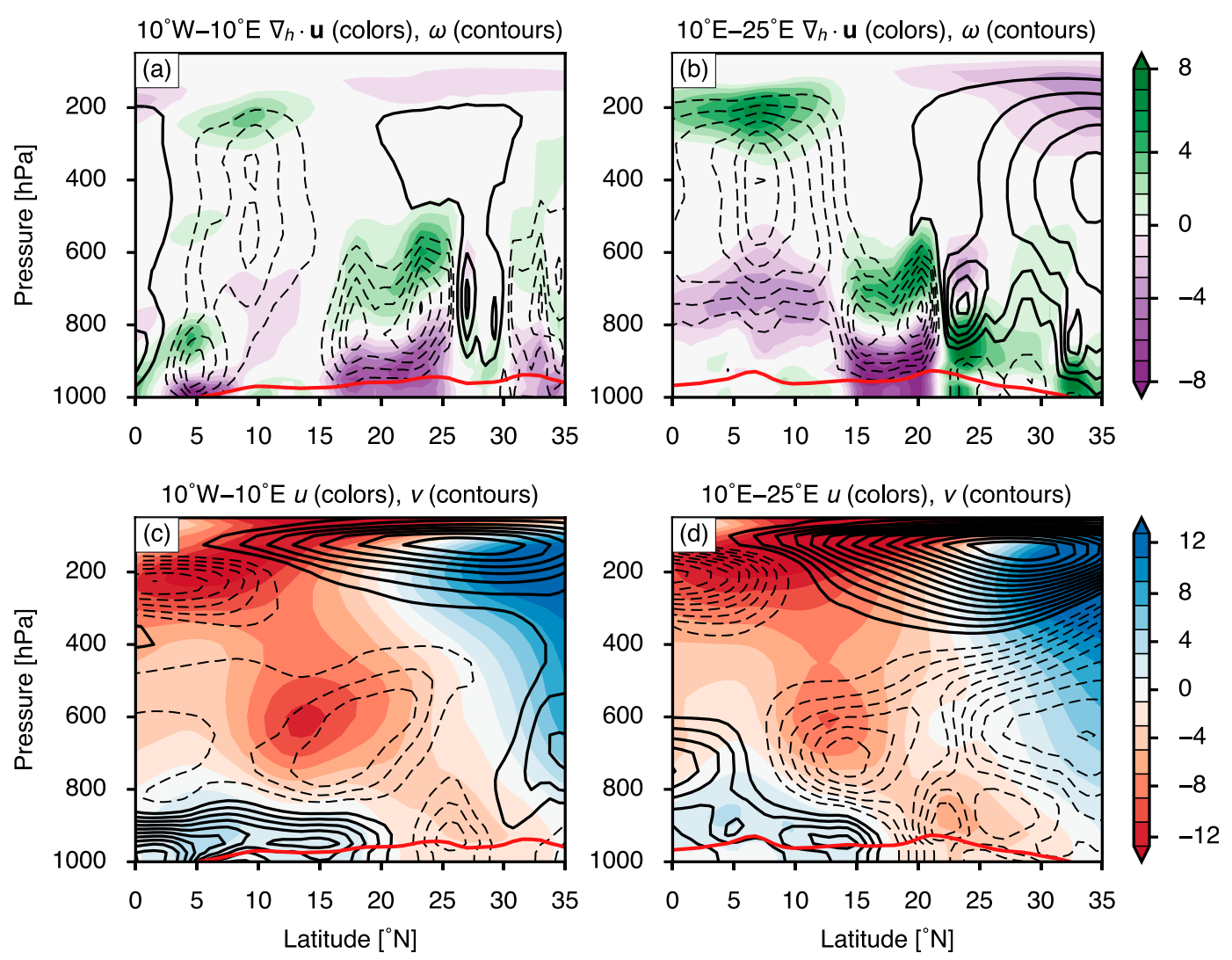

FIG. A1. ERA-Interim JAS climatology zonally averaged separately in the western $\left(10^{\circ} \mathrm{W}-10^{\circ} \mathrm{E}\right)$ and eastern $\left(10^{\circ}-\right.$ $25^{\circ} \mathrm{E}$ ) sections of the analysis domain. (a) Divergence (colors; $10^{-6} \mathrm{~s}^{-1}$ ) and pressure velocity $\omega$ (contours every $0.5 \mathrm{hPa} \mathrm{h}^{-1}$ ) averaged over western longitudes. (b) Divergence and pressure velocity over eastern longitudes. Zonal wind $u$ (colors) and meridional wind $v$ (contours every $\mathrm{m} \mathrm{s}^{-1}$ ) over (c) western longitudes and (d) eastern longitudes. In all panels, zero contours are omitted, and negative contours are dashed.

Guinea region influenced our decision to use $10^{\circ} \mathrm{N}$ as the southern boundary when calculating areaaveraged, layer-integrated divergence so that this uncertain region is excluded. Even if the reanalyses have a biased representation of interannual variability in this region, it seems unlikely that this is large enough to change our broad conclusions (e.g., the sign of correlations between Sahel precipitation and geopotential height, divergence, and Saharan ascent would need to be wrong in two reanalysis products). Confirmation of some of these associations in an idealized model lends further confidence to our results. Nevertheless, it is good to bear in mind that reanalyses have bias, even while they remain a useful tool for understanding historical atmospheric variability over the last few decades.

Important questions remain. Does the association between a weak Saharan SMC and increased Sahel rainfall result from a time average of a similar association on intraseasonal or synoptic time scales?
Answering this question is complicated by the fact that recent studies of subseasonal variability of the Saharan circulation have focused on selecting periods when the regional maximum of LLAT over northwestern Africa (i.e., the darkest green shading in Fig. 5e) had an extreme value (Lavaysse et al. 2009, 2010a,b). This approach tends to select periods with strong near-surface cyclonic flow west of the date line; the concurrent precipitation anomalies are positive over the Gulf of Guinea and the central Sahel but negative over the far western Sahel. That pattern of anomalous rainfall is distinct from the nearly zonally symmetric structure seen when the rainfall itself is used to create composites or regressions (e.g., Fig. 3c). Vizy and Cook (2014) documented an association between surges of cold air across the Sahara and reduced precipitation over the eastern Sahel on both intraseasonal and interannual time scales, but the spatial structures of the precipitation and dynamical anomalies associated with those cold surges 

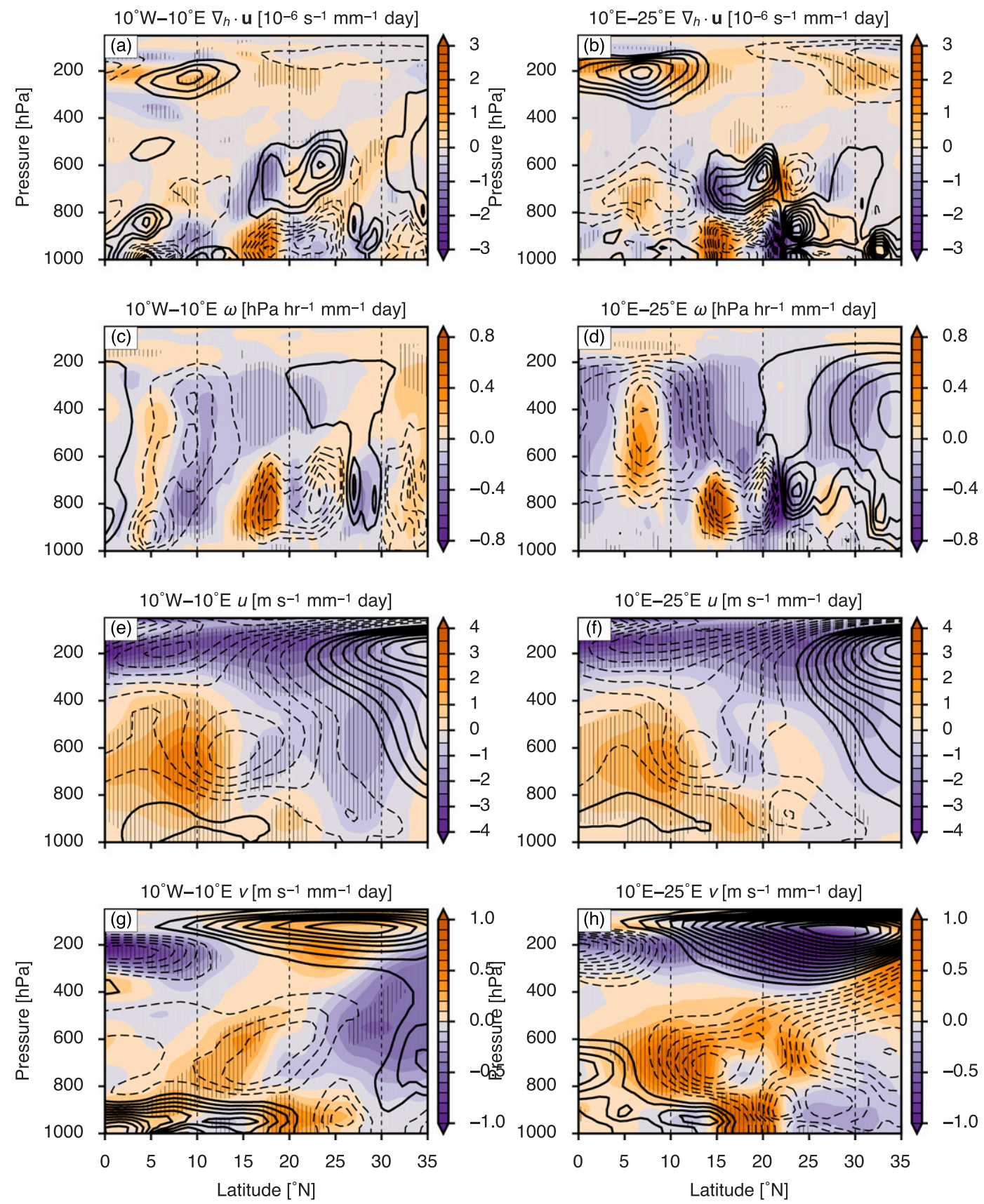

FIG. A2. All panels show ERA-Interim zonal averages over (left) $10^{\circ} \mathrm{W}-10^{\circ} \mathrm{E}$ or (right) $10^{\circ}-25^{\circ} \mathrm{E}$. Colors indicate regression slope onto Sahel precipitation, hatching indicates statistical significance, and black contours indicate climatology (negative dashed, zero omitted). Units on regression slope imply $\mathrm{mm}^{-1}$ day. (a),(b) Horizontal divergence $\left(10^{-6} \mathrm{~s}^{-1}\right.$; contours every 1$) ;(\mathrm{c}),(\mathrm{d}) \omega\left(\mathrm{hPa} \mathrm{h}^{-1}\right.$; contours every $\left.0.5 \mathrm{hPa} \mathrm{h}^{-1}\right) ;$ (e), (f) $u\left(\mathrm{~m} \mathrm{~s}^{-1}\right.$; contours every $\left.2 \mathrm{~m} \mathrm{~s}^{-1}\right)$; and $(\mathrm{g}),(\mathrm{h}) v\left(\mathrm{~m} \mathrm{~s}^{-1}\right.$; contours every $\left.0.5 \mathrm{~m} \mathrm{~s}^{-1}\right)$.

were very different from those of the anomalies we studied here. Although the mechanisms of subseasonal variability are important, there is a long tradition of using two-dimensional models of atmospheric meridional overturning circulations to represent the seasonal-mean West African monsoon (e.g., Charney et al. 1975; Zheng and Eltahir 1998). Our results disprove the idea that a stronger Saharan SMC causes enhanced Sahel rainfall in the summer mean (e.g., Martin and Thorncroft 2014) and are instead consistent with the idea that the SMC inhibits Sahel rainfall by mixing dry air into that region. 
Acknowledgments. We thank Ned Vizy, Amato Evan, and one anonymous reviewer for their work in improving the manuscript. Both authors were supported by National Science Foundation Grant AGS-1253222. This work was supported in part by the facilities and staff of the Yale University Faculty of Arts and Sciences High Performance Computing Center. Computing support was also provided by Yellowstone (http://n2t.net/ark:/85065/ d7wd3xhc), supported by NCAR's Computational and Information Systems Laboratory. We would also like to thank Xavier Levine for many fruitful discussions.

\section{APPENDIX}

\section{Zonal Similarities and Differences}

Recent work has focused on the relationship between the Saharan heat low in the western Sahara and its relationship to precipitation over the Sahel (e.g., Lavaysse et al. 2016). In section 4, we show there is also a region of enhanced LLAT in the eastern Sahara, extending along the $20^{\circ} \mathrm{N}$ parallel (Fig. 5e). Although this feature in the eastern Sahara is not commonly called the SHL - that term seems to be reserved for the heat low in the western Sahara-a heat low circulation is nevertheless present in the eastern Sahara (Figs. A1a,b). This circulation includes an SMC marked by near-surface horizontal convergence, shallow ascent, and midlevel horizontal divergence. In the western Sahara, the shallow ascent extends from approximately $15^{\circ}-25^{\circ} \mathrm{N}$, while in the eastern Sahara, it is more meridionally confined, extending from approximately $14^{\circ}-22^{\circ} \mathrm{N}$. The deep circulation also exhibits some zonal inhomogeneity: as one moves east across Africa, the ITCZ shifts closer to the equator and is associated with more intense and meridionally broader ascent. The ITD, as measured by the zero in near-surface meridional wind (Figs. A1c,d) also moves toward the equator as one moves east. This is consistent with the slight tilt of the low-level geopotential trough shown in Fig. 5a.

Fig. A2 shows dynamical fields zonally averaged over the western and the eastern parts of our analysis domain regressed on our standard Sahel precipitation time series; no meaningful differences are found when using precipitation indices derived separately from the eastern and western portions of the domain (not shown). Regressions of horizontal divergence (Figs. A2a,b) show the SMC shifts north in both the eastern and western portions of the domain, but the shift is more pronounced and statistically significant in the eastern portions of the domain. In contrast, the western part of the domain exhibits more of a weakening of the southern half of the SMC. Regressions of pressure velocity (Figs. A2c,d) show essentially the same picture, with the SMC shift showing a dipole in both eastern and western regions, but anomalous subsidence dominating the western region and ascent dominating the eastern region. This shows that if one were to consider the western region alone, the region with the SHL, wet years would be associated with a decrease in the upward shallow mass flux in the SHL. Thus, our conclusion that the SMC weakens during wet Sahel years becomes even stronger when one limits the analysis to the western part of our domain. Averaging over a broader zonal region makes the meridional dipole in anomalous shallow ascent (Fig. 8f) show greater meridional antisymmetry.

There is a great deal of similarity between the zonal wind anomalies in the eastern and western regions (Figs. A2e,f), although the barotropic subtropical jet seems to change more in the western region. The southward wind at $700 \mathrm{hPa}$ (the top of the SMC) is stronger in the eastern domain because that region lies on the eastern edge of the 700-hPa anticyclone (Figs. A2g,h); the southward 700-hPa wind over the Sahel weakens more in the eastern region during wet years, providing yet another indicator of the weakening of the entire shallow circulation over the Sahara.

\section{REFERENCES}

Adler, R. F., and Coauthors, 2003: The version-2 Global Precipitation Climatology Project (GPCP) Monthly Precipitation Analysis (1979-present). J. Hydrometeor., 4, 1147-1167, doi:10.1175/1525-7541(2003)004<1147:TVGPCP>2.0.CO;2.

Biasutti, M., A. H. Sobel, and S. J. Camargo, 2009: The role of the Sahara low in summertime Sahel rainfall variability and change in the CMIP3 models. J. Climate, 22, 5755-5771, doi:10.1175/2009JCLI2969.1.

Charney, J., P. H. Stone, and W. J. Quirk, 1975: Drought in the Sahara: A biogeophysical feedback mechanism. Science, 187, 434-435, doi:10.1126/science.187.4175.434.

Dee, D. P., and Coauthors, 2011: The ERA-Interim reanalysis: Configuration and performance of the data assimilation system. Quart. J. Roy. Meteor. Soc., 137, 553-597, doi:10.1002/ qj. 828 .

Derbyshire, S., I. Beau, P. Bechtold, J.-Y. Grandpeix, J.-M. Piriou, J.-L. Redelsperger, and P. Soares, 2004: Sensitivity of moist convection to environmental humidity. Quart. J. Roy. Meteor. Soc., 130, 3055-3079, doi:10.1256/qj.03.130.

Döös, K., and J. Nilsson, 2011: Analysis of the meridional energy transport by atmospheric overturning circulations. J. Atmos. Sci., 68, 1806-1820, doi:10.1175/2010JAS3493.1.

Eltahir, E. B., and C. Gong, 1996: Dynamics of wet and dry years in West Africa. J. Climate, 9, 1030-1042, doi:10.1175/ 1520-0442(1996)009<1030:DOWADY>2.0.CO;2.

Evan, A. T., C. Flamant, C. Lavaysse, C. Kocha, and A. Saci, 2015: Water vapor forced greenhouse warming over the Sahara Desert and the recent recovery from the Sahelian drought. J. Climate, 28, 108-123, doi:10.1175/JCLI-D-14-00039.1. 
Folland, C. K., T. N. Palmer, and D. E. Parker, 1986: Sahel rainfall and worldwide sea temperatures, 1901-85. Nature, 320, 602 607, doi:10.1038/320602a0.

Gelaro, R., and Coauthors, 2017: The Modern-Era Retrospective Analysis for Research and Applications, version 2 (MERRA-2). J. Climate, 30, 5419-5454, doi:10.1175/ JCLI-D-16-0758.1.

Giannini, A., R. Saravanan, and P. Chang, 2003: Oceanic forcing of Sahel rainfall on interannual to interdecadal time scales. Science, 302, 1027-1030, doi:10.1126/science.1089357.

Haarsma, R. J., F. M. Selten, S. L. Weber, and M. Kliphuis, 2005: Sahel rainfall variability and response to greenhouse warming. Geophys. Res. Lett., 32, L17702, doi:10.1029/2005GL023232.

Hagos, S. M., and K. H. Cook, 2007: Dynamics of the West African monsoon jump. J. Climate, 20, 5264-5284, doi:10.1175/ 2007JCLI1533.1.

Holloway, C., and J. D. Neelin, 2009: Moisture vertical structure, column water vapor, and tropical deep convection. J. Atmos. Sci., 66, 1665-1683, doi:10.1175/2008JAS2806.1.

Hurley, J. V., and W. R. Boos, 2013: Interannual variability of monsoon precipitation and local subcloud equivalent potential temperature. J. Climate, 26, 9507-9527, doi:10.1175/ JCLI-D-12-00229.1.

Kalnay, E., and Coauthors, 1996: The NCEP/NCAR 40-Year Reanalysis Project. Bull. Amer. Meteor. Soc., 77, 437-471, doi:10.1175/1520-0477(1996)077<0437:TNYRP>2.0.CO;2.

Lavaysse, C., C. Flamant, S. Janicot, D. J. Parker, J. P. Lafore, B. Sultan, and J. Pelon, 2009: Seasonal evolution of the West African heat low: A climatological perspective. Climate Dyn., 33, 313-330, doi:10.1007/s00382-009-0553-4.

,$- \ldots$, and - 2010a: Regional-scale convection patterns during strong and weak phases of the Saharan heat low. Atmos. Sci. Lett., 11, 255-264, doi:10.1002/asl.284.

,,--- , and P. Knippertz, 2010b: Links between African easterly waves, midlatitude circulation and intraseasonal pulsations of the West African heat low. Quart. J. Roy. Meteor. Soc., 136, 141-158, doi:10.1002/qj.555.

- - - A. Evan, S. Janicot, and M. Gaetani, 2016: Recent climatological trend of the Saharan heat low and its impact on the West African climate. Climate Dyn., 47, 3479-3498, doi:10.1007/s00382-015-2847-z.

Losada, T., B. Rodriguez-Fonseca, E. Mohino, J. Bader, S. Janicot and C. R. Mechoso, 2012: Tropical SST and Sahel rainfall: A non-stationary relationship. Geophys. Res. Lett., 39, L12705, doi:10.1029/2012GL052423.

Martin, E. R., and C. D. Thorncroft, 2014: The impact of the AMO on the West African monsoon annual cycle. Quart. J. Roy. Meteor. Soc., 140, 31-46, doi:10.1002/qj.2107.

Met Office, 2015: Iris Version 1.8. Met Office. [Available online at http://scitools.org.uk/.]

Neelin, J. D., and N. Zeng, 2000: A quasi-equilibrium tropical circulation model-Formulation. J. Atmos. Sci., 57, 1741-1766, doi:10.1175/1520-0469(2000)057<1741:AQETCM>2.0.CO;2.

Nicholson, S. E., 2013: The West African Sahel: A review of recent studies on the rainfall regime and its interannual variability ISRN Meteor., 2013, 453521, doi:10.1155/2013/453521.

— rainfall variability in the West African Sahel on interannual and interdecadal timescales. Int. J. Climatol., 21, 1733-1757, doi:10.1002/joc.648.

Nie, J., W. R. Boos, and Z. Kuang, 2010: Observational evaluation of a convective quasi-equilibrium view of monsoons. J. Climate, 23, 4416-4428, doi:10.1175/2010JCLI3505.1.
Nolan, D. S., C. Zhang, and S.-H. Chen, 2007: Dynamics of the shallow meridional circulation around intertropical convergence zones. J. Atmos. Sci., 64, 2262-2285, doi:10.1175/ JAS3964.1.

S. W. Powell, C. Zhang, and B. E. Mapes, 2010: Idealized simulations of the intertropical convergence zone and its multilevel flows. J. Atmos. Sci., 67, 4028-4053, doi:10.1175/ 2010JAS3417.1.

Parker, D. J., P. Willetts, C. Birch, A. G. Turner, J. H. Marsham, C. M. Taylor, S. Kolusu, and G. M. Martin, 2016: The interaction of moist convection and mid-level dry air in the advance of the onset of the Indian monsoon. Quart. J. Roy. Meteor. Soc., 142, 2256-2272, doi:10.1002/ qj.2815.

Peyrillé, P., and J.-P. Lafore, 2007: An idealized two-dimensional framework to study the West African Monsoon. Part II: Large-scale advection and the diurnal cycle. J. Atmos. Sci., 64, 2783-2803, doi:10.1175/JAS4052.1.

—,- , and J.-L. Redelsperger, 2007: An idealized twodimensional framework to study the West African Monsoon. Part I: Validation and key controlling factors. J. Atmos. Sci., 64, 2765-2782, doi:10.1175/JAS3919.1.

— - , and A. Boone, 2016: The annual cycle of the West African monsoon in a two-dimensional model: Mechanisms of the rain-band migration. Quart. J. Roy. Meteor. Soc., 142, 1473-1489, doi:10.1002/qj.2750.

Pu, B., and K. H. Cook, 2012: Role of the West African westerly jet in Sahel rainfall variations. J. Climate, 25, 2880-2896, doi:10.1175/JCLI-D-11-00394.1.

Rácz, Z., and R. K. Smith, 1999: The dynamics of heat lows. Quart. J. Roy. Meteor. Soc., 125, 225-252, doi:10.1002/ qj.49712555313.

Rousseeuw, P. J., and A. M. Leroy, 2005: Robust Regression and Outlier Detection. John Wiley \& Sons, 329 pp.

Schneider, T., T. Bischoff, and G. H. Haug, 2014: Migrations and dynamics of the intertropical convergence zone. Nature, 513, 45-53, doi:10.1038/nature13636.

Seabold, S., and J. Perktold, 2010: Statsmodels: Econometric and statistical modeling with Python. Proc. Ninth Python in Science Conf., Austin, TX, Enthought, 57-61. [Available online at http://conference.scipy.org/proceedings/scipy2010/seabold. html.]

Shekhar, R., and W. R. Boos, 2016: Improving energy-based estimates of monsoon location in the presence of proximal deserts. J. Climate, 29, 4741-4761, doi:10.1175/JCLI-D-15-0747.1.

Skamarock, W. C., and Coauthors, 2008: A description of the Advanced Research WRF version 3. NCAR Tech. Note NCAR/TN-475+STR, 113 pp., doi:10.5065/D68S4MVH.

Sobel, A. H., and T. Schneider, 2009: Single-layer axisymmetric model for a Hadley circulation with parameterized eddy momentum forcing. J. Adv. Model. Earth Syst., 1, 10, doi:10.3894/ JAMES.2009.1.10.

Thorncroft, C. D., and M. Blackburn, 1999: Maintenance of the African easterly jet. Quart. J. Roy. Meteor. Soc., 125, 763-786, doi:10.1002/qj.49712555502.

— , H. Nguyen, C. Zhang, and P. Peyrillé, 2011: Annual cycle of the West African monsoon: Regional circulations and associated water vapour transport. Quart. J. Roy. Meteor. Soc., 137, 129-147, doi:10.1002/qj.728.

Trenberth, K. E., D. P. Stepaniak, and J. M. Caron, 2000: The global monsoon as seen through the divergent atmospheric circulation. J. Climate, 13, 3969-3993, doi:10.1175/ 1520-0442(2000)013<3969:TGMAST $>2.0 . \mathrm{CO} ; 2$ 
Vizy, E. K., and K. H. Cook, 2009: A mechanism for African monsoon breaks: Mediterranean cold air surges. J. Geophys. Res., 114, D01104, doi:10.1029/2008JD010654.

- and — , 2014: Impact of cold air surges on rainfall variability in the Sahel and wet African tropics: A multi-scale analysis. Climate Dyn., 43, 1057-1081, doi:10.1007/s00382-013-1953-z.

_ and 2017: Seasonality of the observed amplified Sahara warming trend and implications for Sahel rainfall. J. Climate, 30, 3073-3094, doi:10.1175/JCLI-D-16-0687.1.

Waskom, M., and Coauthors, 2016: Seaborn Version 0.7.0. Zenodo, doi:10.5281/zenodo.45133.

Xie, S.-P., and N. Saiki, 1999: Abrupt onset and slow seasonal evolution of summer monsoon in an idealized GCM simulation. J. Meteor. Soc. Japan, 77, 949-968, doi:10.2151/jmsj1965.77.4_949.
C. Deser, G. A. Vecchi, J. Ma, H. Teng, and A. T. Wittenberg, 2010: Global warming pattern formation: Sea surface temperature and rainfall. J. Climate, 23, 966-986, doi:10.1175/2009JCLI3329.1.

Zhang, C., M. McGauley, and N. A. Bond, 2004: Shallow meridional circulation in the tropical eastern Pacific. J. Climate, 17, 133-139, doi:10.1175/1520-0442(2004)017<0133: SMCITT $>2.0 . C O ; 2$.

- D. S. Nolan, C. D. Thorncroft, and H. Nguyen, 2008: Shallow meridional circulations in the tropical atmosphere. J. Climate, 21, 3453-3470, doi:10.1175/2007JCLI1870.1.

Zheng, X., and E. A. B. Eltahir, 1998: The role of vegetation in the dynamics of West African monsoons. J. Climate, 11, 20782096, doi:10.1175/1520-0442-11.8.2078. 